\title{
EXAMEN DE LAS FUENTES PARA EL ESTUDIO DE LA HISTORIA DEL MATRIMONIO Y DE LAS UNIONES PERMANENTES: UNA APROXIMACIÓN DESDE NAVARRA
}

\author{
Roldán Jimeno Aranguren
}

\begin{abstract}
Sumario: 1. Introducción. 2. LA COSTUMBre. 3. Fuentes LEGISLATIVAS CIVILES. 4. FUENTES LEGISLATIVAS CANÓNICAS. 5. DOCUMENTACIÓN PROCESAl. 6. DoCUMENTACiÓN NOTARIAL. 7. REgistros DE COMPTOS. 8. VisitAS PASTORALES O EPISCOPALES. 9. REGISTROS PARROQUIALES Y REGISTROS CIVILES. 10. FuENTES DOCTRINALES. 10.1. La historiografía del Derecho. 10.2. La historiografía elaborada desde el iuspositivismo. 10.3. La historiografia canónica. 10.4. La historiografía social y de las mentalidades. 10.5. La historiografía de género. 10.6. Antropología social, Sociología y Sociología del Derecho.
\end{abstract}

\section{INTRODUCCIÓN}

El matrimonio, una de las instituciones de Derecho privado que mayor unidad ha poseído en Occidente, ha sido objeto de múltiples estudios iushistóricos. Es nuestro objetivo abordar el examen de las fuentes del matrimonio y de las uniones afines a través del ejemplo de Navarra, un territorio sumamente interesante en relación a este objeto de estudio, pues, el Fuero Nuevo de 1973 ha sido calificado, no sin razón, como la más historicista de todas las compilaciones forales españolas ${ }^{1}$. A pesar de este marcado carácter, las cos-

${ }^{1}$ Cfr. Clavero Salvador, B., El código y el Fuero. De la cuestión regional en la España contemporánea, Siglo XXI, Madrid, 1982, pp. 32-33, nota 22. 
tumbres jurídicas navarras en materia de régimen económico-matrimonial no siempre fueron bien contextualizadas en las leyes del aludido texto foral. Solo a través de un correcto tratamiento del conjunto de las fuentes del derecho alcanzaremos a observar la persistencia de ciertas figuras históricas y podremos ponderar su continuidad hasta el derecho actual, de ahí que un conocimiento exhaustivo de las fuentes iushistóricas contribuirá a explicar mejor el legado del régimen matrimonial histórico navarro en el ordenamiento jurídico vigente y el papel que debería desempeñar la Historia del Derecho en las futuras revisiones legislativas.

En el presente trabajo observaremos las fuentes del Derecho más relevantes para reconstruir la evolución histórica de la institución matrimonial y de la de las parejas estables de Navarra, que son, en concreto, las siguientes: la costumbre; el derecho local (fueros locales, ordenanzas municipales y actas concejiles o municipales); la legislación territorial (en concreto, el Fuero General de Navarra y sus dos Amejoramientos, el Fuero Reducido, los Fors et costumas de la Baja Navarra, la legislación de Cortes, los autos acordados del Consejo Real y los capítulos de visita); la legislación canónica, con especial atención a las constituciones sinodales de las diócesis radicadas en Navarra; la legislación secular contemporánea; y las fuentes procesales. Trataremos también sobre la documentación notarial, los registros de Comptos, los registros parroquiales y civiles, y las fuentes estadísticas.

Otorgaremos una especial atención a las fuentes doctrinales relativas a la historia del matrimonio. El estado de la cuestión está protagonizado en Navarra por civilistas y por historiadores sociales; y carecemos prácticamente de estudios desarrollados por historiadores del Derecho.

\section{LA COSTUMBRE}

La costumbre ha poseído siempre en Navarra una primacía en la prelación de fuentes, si bien, en relación al matrimonio, su importancia fue cada vez menor, fruto, por una parte, de la progresiva institucionalización del Derecho canónico y, por otra, de la minuciosa legislación local y general sobre el régimen económico-matrimonial. Quedaron, sin embargo, algunos ámbitos estrictamente consuetudinarios, como la regulación de la casa o como el régimen económico de la comunidad familiar de bienes, precedente de la actual sociedad familiar de conquistas. Cabe recordar que las Ordenanzas del Real Consejo de Navarra compiladas por Martín de Eusa en 1622, recogieron la disposición de que «fuero, usos y costumbres sean observados y guardados y preferidos a todo Derecho canónico y civil», según ordenanza de Carlos V (IV de Navarra)². Por tanto, la

${ }^{2}$ Eusa, M. de (comp.), Ordenanzas del Conseio Real del Reyno de Navarra, Nicolás de Assiáyn, Pamplona, 1622, lib. 3, tít. 1, ordenanza 1ª, p. 239. 
costumbre ocupó el primer lugar en el orden de prelación de las fuentes del Derecho navarro, por delante del derecho escrito ${ }^{3}$. Algunas leyes dieron por supuesta la existencia de costumbres contrarias a normas escritas. En lo que concierne al ámbito de nuestro estudio, resulta inexcusable la cita a la ley 41 de las Cortes de Pamplona de 1688, que, frente al sistema legitimario del Fuero General, reconocía la existencia de la libertad de testar y de la institución en la legítima foral «por uso, estilo, y costumbre inconcusa e inviolablemente observada de tiempo inmemorial a esta parte» ${ }^{4}$.

El Derecho consuetudinario matrimonial fue decreciendo en importancia conforme avanzó la Edad Contemporánea. Como en el Antiguo Régimen, los únicos ámbitos en los que operó la costumbre fueron la casa y, hasta su positivización en el Fuero Nuevo de 1973, el régimen económico de la sociedad familiar de conquistas. La costumbre relativa a la institución matrimonial carece prácticamente de espacio en la Compilación navarra, pero no está de más recordar que la ley 2 del Fuero Nuevo sitúa a la costumbre en el primer lugar de la prelación de fuentes, y que la ley 3 define su ámbito de aplicación señalando que «la costumbre que no se oponga a la moral o al orden público, aunque sea contra ley, prevalece sobre el Derecho escrito. La costumbre local tiene preferencia respecto a la general. La costumbre que no sea notoria deberá ser alegada y probada ante los Tribunales». En estas cuatro décadas de vigencia de la Compilación no se ha dictado ninguna sentencia judicial en la que se invocara la costumbre en materia matrimonial o económico-matrimonial.

Por su parte, la Etnografía ha evidenciado la existencia, al menos durante el siglo XIX y primera mitad del XX, de diferentes prácticas consuetudinarias vinculadas al matrimonio, como, por ejemplo, lo que se vino a denominar el «matrimonio a vistas», es decir, un enlace convenido entre las dos familias, por el que en ocasiones los contrayentes podían hasta no conocerse personalmente, algo habitual en los siglos medievales y modernos ${ }^{5}$.

${ }^{3}$ De Pablo Contreras, P. V., «Las fuentes del Derecho civil navarro en la nueva configuración del régimen foral», Revista Jurídica de Navarra, Vol. 6/2, 1988, pp. 141147. Monreal Zia, G. y Jimeno Aranguren, R., Textos histórico-jurídicos navarros. I. Historia Antigua y Medieval, Gobierno de Navarra, Pamplona, 2008, pp. 402, 432-441; y Textos histórico-jurídicos navarros. II. Historia Moderna, Gobierno de Navarra, Pamplona, 2011, p. 273.

${ }^{4}$ Elizondo, J. de (comp.), Novíssima Recopilación de las Leyes del Reino de Navarra hechas en sus Cortes Generales desde el año de 1512 hasta el de 1716 inclusive, Oficina de Joseph Joachín Martínez, Pamplona, 1735, lib. 3, tít. 13, ley. 16.

5 ETNIKER EusKalerria, Ritos del nacimiento al matrimonio, Colecc. Atlas etnográfico de Vasconia, no 9, Instituto Labayru, Bilbao, 1998, pp. 409-411. 


\section{FUENTES LEGISLATIVAS CIVILES}

Diversos fueros locales navarros regularon la institución matrimonial o su régimen económico y las diferentes uniones permanentes en la Edad Media. En concreto, los fueros que trataron con mayor o menor intensidad sobre el matrimonio y el amancebamiento fueron los breves de frontera (Caparroso, Marañón, Encisa y Peralta), la familia del fuero de Jaca (Estella, San Sebastián y Pamplona), la familia del fuero de Logroño (Mendavia, Laguardia, San Vicente de la Sonsierra, Antoñana, Bernedo, Labraza, Inzura, Burunda, Vitoria, Arganzón, Viana y Aguilar de Codés), el fuero de Tudela, los fueros de la Novenera, el fuero de Viguera y Val de Funes, el fuero de Medinaceli -extendido a las localidades de Murillo el Fruto y Carcastillo-, el fuero de Carcastillo, el fuero de Daroca - extendido, junto con el de Soria, a las localidades de Cáseda y Peña-, el fuero de Cáseda, el fuero de San Juan de Pie de Puerto (versión del fuero de Bayona), el fuero de Labastida Clairence y el privilegio de franquicia de Etxarri Aranatz. También han de tenerse en cuenta las actas concejiles o municipales y, en menor medida, las ordenanzas municipales, más parcas en información. Por su parte, la legislación territorial navarra del Antiguo Régimen relativa al matrimonio está contenida en el Fuero General y sus dos Amejoramientos, el non nato Fuero Reducido, los Fors et costumas de la Baja Navarra, la legislación de Cortes, los autos acordados del Consejo Real y los Capítulos de visita.

En cuanto a la legislación contemporánea, el restablecimiento del Antiguo Régimen por Fernando VII en 1814 y en 1824 permitió la celebración de las últimas Cortes del reino (1817-1818 y 1828-1829), que se desarrollaron de acuerdo con su composición y atribuciones tradicionales. Dejando a un lado la posible aplicación o no en Navarra de la primera codificación penal reguladora de los delitos de adulterio y amancebamiento (1822), hay que considerar aplicable en nuestro territorio la legislación española en materia matrimonial a partir de la definitiva desaparición del reino y su conversión en provincia española (1839). El Derecho civil propio se mantuvo en la Ley de Fueros de 16 de agosto de 1841. A partir de entonces, los hitos fundamentales de la legislación española fueron el Código penal de 1848 y los diferentes proyectos de Código civil, hasta alcanzar el Sexenio democrático, en el que se introdujo el matrimonio exclusivamente civil por Ley de 18 de julio de 1870. La Restauración echó por tierra este sistema, e implantó en 1875 un matrimonio civil subsidiario, que pasó al Código civil. La Ley Republicana de 28 de junio de 1932 implantó el sistema de matrimonio civil obligatorio, y durante la Guerra civil, el Gobierno de Francisco Franco restableció el sistema de matrimonio civil subsidiario por Ley de 28 de marzo de 1938, que derogó la anterior. La propia dictadura conoció una evolución en estas materias, singularmente a partir de finales de los años sesenta, fruto de las profun- 
das transformaciones sociales del momento, prolegómeno de los cambios de calado producidos en la Transición, a partir de 1977, entre los que destacan el Real Decreto de 1 de diciembre de 1977, que realizó una reforma profunda en el Reglamento del Registro Civil, la Ley 22/1978, de 26 de mayo. La Constitución española tipificó el ius connubii como un Derecho constitucional, y uno de los acuerdos firmados entre la Santa Sede y el Estado español el 3 de febrero de 1979 contempló el matrimonio canónico con efectos civiles ${ }^{6}$.

En todo el período de la codificación civil española y el posterior proceso de apéndices primero y compilador después, se produjeron un buen número de fuentes caracterizadas por su profundo historicismo. En concreto, en el proceso de la elaboración del apéndice navarro al Código civil, habremos de citar la Memoria de Antonio Morales de 1884, elaborada con el fin de identificar las excepciones navarras al Proyecto de Código civil de $1880^{7}$, el Proyecto de Antonio Morales titulado Leyes especiales de Navarra $(1900)^{8}$, el Proyecto de los miembros de la Comisión de letrados de Navarra, Javier García Echarri, Carlos Isaba, Fermín Iñarra y Echenique, Arturo Campión y Salvador Echaide, titulado Proyecto de Apéndice de Navarra al Código civil (1900), el Anteproyecto de Apéndice para Navarra, de Víctor Covián y Junco (1917) ${ }^{10}$, el Informe sobre el Proyecto de Apéndice de Navarra al Código Civil, del Colegio de Abogados de Pamplona (1926) ${ }^{11}$, el Anteproyecto de Apéndice de Navarra al Código civil, de

${ }^{6}$ A partir de entonces, las novedades más destacadas -sobradamente conocidas- han sido la Ley 11/1981, de 13 de mayo, que modificó el Código civil en materia de filiación, patria potestad y régimen económico del matrimonio, la Ley 30/1981, de 7 de julio, relativa al divorcio, los diferentes Acuerdos con religiones distintas de la católica para la celebración del matrimonio (1992), la Ley 35/1994, que autorizó a los alcaldes a celebrar matrimonios, la Ley 1/2000, de 7 de enero, de Enjuiciamiento Civil, la Ley 13/2005, de 1 de julio, que autorizó el matrimonio homosexual, y la Ley 15/2005, de 8 de julio, por la que se modificaron el Código civil y la Ley de Enjuiciamiento Civil en materia de separación y divorcio.

7 Morales Gómez, A., Memoria que comprende los principios e instituciones del Derecho civil de Navarra que deben quedar subsistentes como excepción del Código general, y los que pueden desaparecer viniendo a la unificación, Imprenta de V. Cantera, Pamplona, 1884.

${ }^{8}$ Morales, A., Leyes especiales de Navarra, Imprenta Provincial, Pamplona, 1900.

9 García y Echarri, J., Isaba, C., IÑarra y Echenique, F., Campión, A., y Echaide, S., Proyecto de Apéndice de Navarra al Código Civil, Imprenta Provincial, Pamplona, 1900. Reed. Imprenta Provincial, Pamplona, 1904.

${ }^{10}$ Covián y Junco, V., Anteproyecto de Apéndice para Navarra, Pamplona, 1917. No llegó a editarse (existe copia mecanografiada en el Colegio Notarial de Pamplona), pero sirvió de base para los trabajos de recopilación posteriores.

${ }^{11}$ Colegio de Abogados de Pamplona, Informe sobre el Proyecto de Apéndice de Navarra al Código Civil, aprobado por la Junta de Gobierno del Ilustre Colegio de Abogados de Pamplona, Imprenta Provincial, Pamplona, 1926. 
Rafael Aizpún Santafé y Fernando de Arvizu Aguado (1929) ${ }^{12}$, el Apéndice de Derecho navarro al Código civil, elaborado por el Ilustre Colegio Notarial de Pamplona, con notas críticas realizadas principalmente por Juan San Juan Otermin (1930) ${ }^{13}$, y el Anteproyecto de Apéndice de Navarra al Código Civil (1944), culminado en el posterior Proyecto de Apéndice de Navarra al Código Civil (1945) ${ }^{14}$.

Por su parte, las fuentes de la Compilación del Derecho civil foral de Navarra y sus modificaciones son el Proyecto de Fuero Recopilado de Navarra $(1959)^{15}$, la Recopilación Privada, elaborada por Juan García-Granero Fernández, José Javier Nagore Yárnoz, Jesús Aizpún Tuero, Álvaro d’Ors Pérez-Peix, José Javier López Jacoiste, José Arregui Gil, Juan Santamaría Ansa y Francisco Salinas Quijada $(1971)^{16}$, la Ley 1/1973, de 1 de marzo, por la que se aprueba la Compilación del Derecho Civil Foral de Navarra' ${ }^{17}$, el Decreto-Ley 19/1975, de 26 de diciembre, sobre modificación de determinadas Leyes de la Compilación del Derecho Civil Foral de Navarra ${ }^{18}$, la Ley Foral 5/1987, de 1 de abril, por la que se modifica la Compilación del Derecho Civil Foral o Fuero Nuevo de Navarra ${ }^{19}$, y la Ley Foral 6/2000, de 3 de julio, para la igualdad jurídica de las parejas estables ${ }^{20}$.

\section{FUENTES LEGISLATIVAS CANÓNICAS}

La legislación conciliar y sinodal constituye la legislación más pegada a la realidad de cada territorio, pues, como ocurre con los fueros y ordenanzas municipales, los sínodos son las asambleas más cercanas al pueblo. El legislador sinodal atendió a los aspectos más oscuros de la sociedad en relación a los diferentes sacramentos; no se fijó en las buenas prácticas de los cristianos,

12 Aizpún Santafé, R. y Arvizu Aguado, F. de, Anteproyecto de Apéndice de Navarra al Código civil, Imprenta Provincial, Pamplona, 1930.

13 Colegio Notarial de Pamplona, Apéndice de Derecho navarro al Código civil, Colegio Notarial, Pamplona, 1930.

14 Diputación Foral de Navarra, Proyecto de Apéndice de Navarra al Código Civil, Imprenta Provincial, Pamplona, 1945.

15 Comisión compiladora de Navarra, Proyecto de Fuero Recopilado de Navarra o Compilación del Derecho civil de Navarra, Imprenta Provincial, Pamplona, 1959.

16 García-Granero Fernández, J. et alii, Derecho Foral de Navarra. Derecho privado (Recopilación privada), Aranzadi-Diputación Foral de Navarra, Pamplona, 1971.

${ }_{17}$ Boletín Oficial del Estado, 7, 8, 9, 10, 12, 13 y 14 de marzo de 1973, n 57 a 63; corrección de errores Boletín Oficial del Estado, 30 de mayo de 1974, nº 129.

${ }_{18}$ Boletín Oficial del Estado, 8 de enero de 1976, $\mathrm{n}^{\circ} 7$.

19 Boletín Oficial del Estado, 5 de junio de 1987, $\mathrm{n}^{\circ} 134$.

${ }^{20}$ Boletín Oficial de Navarra, 7 de julio de 2000, $\mathrm{n}^{\circ}$ 82, y Boletín Oficial del Estado, 6 de septiembre de $2000, \mathrm{n}^{\mathrm{o}} 214$. 
sino en la transgresión de los deberes sacramentales del matrimonio. Esta legislación particular del obispado buscó la corrección de la vida de los fieles conforme a la moral católica. El sacramento matrimonial fue tratado con una profusión cada vez mayor conforme avanzó la Baja Edad Media, hasta que, el Concilio de Trento y su Decreto Tametsi dieron paso a unas constituciones sinodales que regularon con detalle esta materia.

Cabe señalar, por otra parte, que no conocemos recursos planteados desde Navarra ante la Curia romana generados por la exclusividad del Derecho canónico en materia matrimonial, a diferencia de Castilla, donde se recurrió por cuestiones relativas al Tribunal de la Rota o por colisiones con la jurisdicción episcopal ${ }^{21}$.

Las fuentes de los concilios provinciales y de los sínodos diocesanos que afectan al territorio navarro son numerosas, fruto de la diversidad de provincias eclesiásticas y diócesis existentes en el reino a lo largo de su historia, de ahí que hayan de tenerse en cuenta las Constituciones provinciales de Tarragona, Zaragoza y Auch, y las Constituciones sinodales de las diócesis de Pamplona, Calahorra, Tarazona, Zaragoza, Bayona y Dax.

\section{DOCUMENTACIÓN PROCESAL}

Los procesos judiciales constituyen la fuente más importante para el análisis de la praxis matrimonial y de la transgresión de la norma. Alejandro Lizarraga consideró que los procesos diocesanos suponen la aplicación más expresiva del Derecho canónico en las diferentes comunidades que integran el territorio, «al tiempo que reflejan de modo directo la vida de una sociedad, cuyos usos, estructuras, conflictos y valores son vertidos en ese intento de plasmar la realidad de las cosas que es siempre un proceso judicial $»^{22}$, aseveración que cabe extrapolar a los procesos del ámbito secular.

No contamos desgraciadamente con procesos medievales, pero abunda la documentación procesal de época moderna. Los procesos de la jurisdicción secular se conservan en el Archivo General de Navarra (sección de Tribunales Reales), y los de la jurisdicción eclesiástica en los diferentes archivos diocesanos, entre los que destacan, por su elevado número, los del Archivo Diocesano de Pamplona de los siglos XVI y XVII suman 1.556 procesos matrimoniales, cuya tipología analizó Juncal Campo, tras un minucioso ras-

${ }^{21}$ Cfr. Rodríguez Gil, M., Curso de Historia del Derecho Español, Iustel, Madrid, 2010 , p. 342.

22 Lizarraga Artola, A., «La praxis acerca del matrimonio en la diócesis de Pamplona antes del Concilio de Trento (1501-1560)», Cuadernos doctorales. Derecho Canónico. Derecho Eclesiástico del Estado, Vol. 9, 1991, p. 322. 
treo cuantificador ${ }^{23}$. No parece, sin embargo, que el método consistente en probar el elemento repetido ${ }^{24}$ se adecúe bien a la Historia del Derecho -al menos desde un planteamiento de longue durée, pues los centenares de procesos judiciales existentes en las diversas jurisdicciones impiden abordar con detalle el contenido de los mismos, faltando para Navarra análisis monográficos centrados unos pocos procesos judiciales, como los desarrollados en Castilla ${ }^{25}$.

Ha de tenerse en cuenta, asimismo, la jurisprudencia del Tribunal del Santo Oficio relativo a la bigamia, con fondos documentales, en este caso, en el Archivo Histórico Nacional, identificados y analizados por Beatriz Tanco ${ }^{26}$.

Contamos, por otra parte, con alegaciones jurídicas históricas que tienen que ver con la institución matrimonial. En concreto, el Archivo General de Navarra custodia el códice Allegaciones iuris, formado por una colección de diversas alegaciones, informaciones y dictámenes jurídicos sobre diversos asuntos contenciosos del siglo XVII y de principios del XVIII, sobre todo relativas a Derecho civil. La mayor parte de ellas abordan casos de la Ribera tudelana, como el relativo a la sucesión de bienes troncales, publicado y analizado por Roldan Jimeno y María Iranzu Rico ${ }^{27}$.

En cuanto a la jurisprudencia contemporánea, las sentencias de los Tribunales del reino alcanzan hasta la desaparición del Consejo Real y la Corte Mayor en 1834 -aunque perviven todavía sus nombres asimilado ahora al sistema español, y, definitivamente con la Ley de Fueros de 1841. Las sentencias fueron dictadas a partir de entonces por el Tribunal Supremo de Justicia, la Audiencia Territorial y los Juzgados de Primera Instancia e Instrucción.

La codificación española acabó circunscribiendo la regulación del matrimonio navarro al Derecho económico matrimonial. El repertorio de la juris-

${ }^{23}$ Campo Guinea, M ${ }^{\mathrm{a}}$ del J., Comportamientos matrimoniales en Navarra. Siglos XVI y XVII, Gobierno de Navarra, Pamplona, 1998.

${ }_{24}$ Vid., Chaunu, P., Historia cuantitativa, historia serial, Fondo de Cultura Económica, México, 1987.

${ }^{25}$ Collantes de Terán de la Hera, Ma J., El amancebamiento. Una visión histórico-jurídica en la Castilla moderna, Dykinson, Madrid, 2014, donde, entre otras cuestiones, analizó dos procesos sobre amancebamiento de finales del siglo XVIII.

26 TANCO MARTínez, Beatriz, «La bigamia en el Tribunal Inquisitorial de Logroño: siglos XVI y XVII», en ERro Gasca, C. y Mugueta Moreno, I. (coords.), Grupos sociales en la historia de Navarra, relaciones y derechos. Actas del V Congreso de Historia de Navarra. Pamplona, septiembre de 2002, Ediciones Eunate, Pamplona, 2002, vol. 1, pp. 333-342.

27 Jimeno Aranguren, R. y Rico Arrastia, Ma I., «La sucesión de los bienes troncales en Tudela (Navarra) a la luz de un dictamen jurídico de finales del siglo XVII», Ius Fugit. Revista de Estudios Histórico-Jurídicos de la Corona de Aragón, Vol. 17, 20112014, pp. 191-210. 
prudencia civil de Navarra, dirigido por Francisco de Asís Sancho Rebullida, comprende decenas de sentencias del Tribunal Supremo y de la Audiencia de Navarra relativas al régimen económico matrimonial ${ }^{28}$.

En el ámbito canónico, los procesos de los siglos XIX y XX de los diversos archivos diocesanos no han sido objeto de estudio.

\section{DOCUMENTACIÓN NOTARIAL}

La praxis del matrimonio histórico, y muy singularmente del régimen económico matrimonial, puede reconstruirse también a través de los documentos de aplicación del derecho, fuente imprescindible para los siglos altomedievales, pues supone prácticamente el único testimonio documental de que disponemos para acercarnos a la institución. Tenemos la fortuna de contar con toda la documentación alto y plenomedieval navarra publicada, y un buen número de fuentes bajomedievales también están transcritas. Frente a las escasas capitulaciones matrimoniales medievales conservadas -la fuente más interesante para el estudio del régimen económico-matrimonial-, abundan las de épocas moderna y contemporánea, con miles de contratos conservados en la sección Protocolos notariales del Archivo General de Navarra. El investigador ha de tener en cuenta que los protocolos notariales adquieren carácter histórico transcurridos cien años desde su elaboración, por lo que en el mencionado Archivo únicamente se pueden consultar los fondos hasta el año 1915. La fecha coincide, prácticamente, con la del magnífico estudio de Hilario Yaben, Los contratos matrimoniales en Navarra y su influencia en la estabilidad de la familia $(1916)^{29}$.

\section{REGISTROS DE COMPTOS}

Los Registros de Comptos del reino de Navarra, existentes a partir de 1259 y conservados en la sección de Comptos del Archivo General, contienen información sobre la recaudación de penas impuestas con motivo de los delitos por adulterio, rapto y crimen contra natura.

\section{VISITAS PASTORALES O EPISCOPALES}

La visita pastoral del obispo a su diócesis fue una de las instituciones más antiguas de la Iglesia, potenciada por los concilios toledanos y consolidada

${ }^{28}$ SANCho Rebullida, F. de A. (dir.), Jurisprudencia civil foral de Navarra, Gobierno de Navarra, Pamplona, 1997, 3 vols.

29 YABEN Y YABEN, H., Los contratos matrimoniales en Navarra y su influencia en la estabilidad de la familia, Establecimiento tipográfico de Jaime Ratés, Madrid, 1916. 
en la Edad Media merced a su regulación por el Decreto de Graciano y por las Decretales de Gregorio IX, aunque no fue hasta el Concilio de Trento cuando se generalizó la institucionalización y organización de las visitas institución en el ámbito eclesiástico. La Iglesia pudo conocer con este instrumento la realidad de cada diócesis, corregir los comportamientos que transgredían la norma y acopiar información ${ }^{30}$, de ahí que visitas pastorales sean prolijas informando sobre diversos aspectos relativos a la transgresión del Derecho canónico matrimonial. Los mandatos del obispo o de sus comisionados se consignaban en los libros de visitas de cada parroquia. En Navarra contamos con abundantes visitas a partir de los años de la reforma pretridentina y, sobre todo, desde la institucionalización de este mecanismo de control a raíz del Concilio de Trento.

\section{REGISTROS PARROQUIALES Y REGISTROS CIVILES}

Como efecto de la publicidad del futuro matrimonio establecida por el Concilio de Trento se crearon los registros parroquiales, que consignaron el estado civil de los fieles de cada parroquia. Constituyen la única fuente existente para contabilizar el número de matrimonios hasta 1870, cuando con la Ley de Matrimonio Civil se crearon los Registros civiles. A partir de estos últimos se han confeccionado las estadísticas históricas de los matrimonios, divorcios y, en la actualidad, también de las parejas de hecho. Las estadísticas han sido publicadas en la obra Movimiento natural de la población navarra, 1858-198931. Esos datos y los relativos a períodos posteriores se encuentran en la página web del Instituto de Estadística de Navarra ${ }^{32}$, y fueron analizados, para el período 19761991, por la socióloga Carolina Montoro Gurich ${ }^{33}$.

\section{FUENTES DOCTRINALES}

No existe una doctrina jurídica navarra sobre el matrimonio y las uniones afines hasta la época contemporánea, pues autores como Martín de Azpilcue-

\footnotetext{
${ }^{30}$ Vid. CAmpo Guinea, M ${ }^{\mathrm{a}}$ del J., Comportamientos matrimoniales, op.cit., pp. 47-50.

31 Movimiento natural de la población navarra, 1858-1989, Gobierno de Navarra, Pamplona, 1993.

$32<$ http://www.navarra.es/home_es/Navarra/Asi + es + Navarra/Navarra + en + cifras/> (consultado en marzo de 2015).

${ }_{33}$ Montoro Gurich, C., «¿Quién se casa con quién? Mercado matrimonial en primeras nupcias en Navarra, 1976-1991», en Sullivan, D. S. R. (coord.), Actas del Congreso Internacional de la Población. V Congreso de la ADEH, vol. IV. Matrimonio y nupcialidad: perspectivas interdisciplinares, Gobierno de La Rioja-Instituto de Estudios Riojanos, Logroño, 1999, pp. 133-158; La nupcialidad en Navarra. Análisis socio-demográfico 19751991, Rialp, Madrid, 1999.
} 
ta, Bartolomé de Carranza o Juan de Palafox y Mendoza desarrollaron y publicaron sus estudios fuera de su tierra. En el siglo XIX asistimos al alumbramiento de la doctrina navarra de la mano de civilistas, canonistas y iushistoriadores, a los que habremos de añadir, a partir de la segunda mitad del siglo XX, las aportaciones de los historiadores sociales, los antropólogos y los sociólogos.

\subsection{La historiografia del Derecho}

José Yanguas y Miranda puede ser considerado el primer historiador del derecho navarro, a pesar de que no era jurista. Su Diccionario de los Fueros del Reino de Navarra (1828-1829) fue una suerte de primer cedazo delimitador de las fuentes legales relativas al matrimonio y al Derecho económicomatrimonial. Voces de esta obra como «Adulterio», «Donaciones», «Hijos», «Matrimonios», «Sucesiones»y «Usufructo», así como las que incluyó en su posterior Diccionario de Antigüedades del Reino de Navarra (1840-1841) -verbi gracia «Matrimonios»-, constituyeron los primeros micro-estudios iushistóricos sobre la institución matrimonial en Navarra ${ }^{34}$. Su labor fue continuada por un jurista, José Alonso Ruiz de Conejares, que ahondó en la interpretación de las fuentes delimitadas por Yanguas, en su minuciosa compilación y análisis de la legislación que perduró a raíz de la Ley de Fueros de $1841^{35}$.

Las décadas siguientes no alumbraron nuevas aportaciones, hecha salvedad de las referencias generales, pero utilísimas desde una perspectiva comparada, de la obra de Tomás Ximénez de Embún dedicada al derecho altomedieval aragonés y navarro $(1878)^{36}$.

En la última década del siglo XIX aparecieron dos artículos imprescindibles firmados por el normando Georges Desdevises du Dézert: «De la condition de la femme marié en Navarre d'apres le Fuero General» $(1890)^{37}$-sobre

34 Yanguas y Miranda, J., Diccionario de los Fueros del Reino de Navarra y de las leyes vigentes promulgadas hasta las Cortes de los años 1817 y 1818, inclusive, Imprenta de Ignacio Ramón Baroja, San Sebastián, 1828. 3 vols. Adiciones a los diccionarios de los Fueros y leyes del reino de Navarra, Imprenta de Ignacio Ramón Baroja, San Sebastián, 1829. Reed. de ambas en Diputación Foral de Navarra, Pamplona, 1964. 3. vols.

${ }_{35}$ Alonso Ruiz, J., Recopilación y comentario de los Fueros y Leyes del Antiguo Reino de Navarra, que han quedado vigentes después de la modificación hecha por la Ley Paccionada de 16 de agosto de 1841, Saavedra y Compañía, Madrid, 1848-1849. Reed. Diputación Foral de Navarra, Pamplona, 1964, 2 vols.

${ }^{36}$ XIMÉnez de EMbún, T., Ensayo histórico acerca de los orígenes de Aragón y Navarra, Imprenta del Hospicio, Zaragoza, 1878.

37 Desdevises du Dezert, M. G., «De la condition de la femme marié en Navarre d'après le Fuero General», Revue des Pyrénées, 1890, pp. 804-833. 
la condición de la mujer en la familia navarra, tanto durante el matrimonio como tras su disolución-, y «Les unions irrégulieres en Navarre» $(1891)^{38}$, en donde este doctor en Derecho y en Historia subrayó el arcaísmo del matrimonio navarro y las singulares formas de uniones sexuales permanentes.

Ningún historiador del Derecho, navarro, francés o español, continuó investigando el matrimonio navarro, ni siquiera el éuskaro Arturo Campión, que apenas se ocupó de la institución matrimonial en su copiosa obra, más allá de consideraciones vagas y generales ${ }^{39}$. Fueron los estudiosos del Derecho positivo -como veremos más abajo-, los que ahondaron en la historia del matrimonio en las tres primeras décadas del siglo XX. El desinterés por el pasado jurídico del reino pirenaico quedó evidenciado en el cuaderno quinto de Salvador Minguijón, dedicado a la capacidad jurídica, familia, esponsales y matrimonio $(1929)^{40}$, centrado en el Derecho romano, canónico, germano, hispano-godo y castellano medieval.

Los años del franquismo fueron fecundos en el análisis de diversos aspectos de la institución matrimonial y de las uniones sexuales permanentes elaborados a partir de los fueros locales y territoriales hispánicos medievales, incluidos los textos navarros más relevantes. Fueron trabajos muy marcados por el positivismo, entre los que destacamos los realizados por Rafael Gibert (1947, 1951$1952)^{41}$, Juan García González (1953) ${ }^{42}$, José María Font Ríus (1954) ${ }^{43}$, Alfon-

${ }^{38}$ Desdevises du Dezert, M. G., «Les unions irrégulieres en Navarre», Mémoires de la Academie National des Sciences, Arts et Belles Lettres de Caen, 1891, pp. 185-204.

39 Vid., por ejemplo, sus consideraciones sobre la casa y la familia: CAMPIón, A., «La personalidad éuskara en la Historia, el Derecho y la Literatura», Discursos politicos y literarios, La Gran Enciclopedia Vasca, Bilbao, 1976 (orig. Bilbao, 1901), pp. 126-127.

${ }^{40}$ Minguijón, S., Historia del Derecho español, con exposición de instituciones romanas, canónicas y germanaas en su proceso evolutivo y con referencias a la Historia de las ideas y de la civilización. Cuaderno quinto. Capacidad jurídica, familia, esponsales, matrimonio, Gambón, Madrid, 1929 ( $3^{\text {a }}$ edic. aumentada).

${ }^{41}$ GiBERT, R., «El consentimiento familiar en el matrimonio según el Derecho medieval español», Anuario de Historia del Derecho español, Vol. 18, 1947, pp. 706-761; «El Derecho medieval de la Novenera», Anuario de Historia del Derecho español, Vol. 2122, 1951-1952, pp. 1169-1221. Sin embargo, en su antología de textos de derecho histórico privado no optó por ningún fragmento del Fuero General de Navarra para ilustrar los esponsales, el matrimonio, el régimen dotal, las arras y dote, la comunidad de bienes y de ganancias, la potestad paterna, o la sucesión. Sí lo hizo, en cambio, a la hora de ejemplificar la filiación, los alimentos, las sucesiones, la legítima, o la mejora (Textos jurídicos españoles, Gómez, Pamplona, 1954, pp. 101-147).

${ }^{42}$ García GonZÁlez, J., «El incumplimiento de las promesas de matrimonio en la historia del Derecho español», Anuario de Historia del Derecho español, Vol. 23, 1953, pp. 611-642.

${ }^{43}$ FonT Ríus, J. M ${ }^{\mathrm{a}}$, La ordenación paccionada del régimen matrimonial de bienes en el Derecho medieval hispánico, Academia Matritense del Notariado, Madrid, 1954. 
so Otero Varela $(1955,1957-1958)^{44}$, y Rafael Sierra Ruiz (1964-1965, 1965-1966) ${ }^{45}$. Joaquín Cerdá Ruiz de Funes elaboró una síntesis tardía de lo contenido en estos trabajos de derecho local en la voz «Fueros municipales» de la Nueva Enciclopedia Jurídica de Seix $(1976)^{46}$.

La renovación metodológica que por aquellos años venía operándose en Europa, y muy especialmente en Francia, no llegó a España hasta los años setenta. Se relanzaron a partir de entonces trabajos desde orientaciones, presupuestos metodológicos y objetivos dispares. Algunos de los miembros de la nueva generación de historiadores del derecho incorporados a la disciplina en el segundo de los años sesenta o el primero de los setenta que se ocuparon del matrimonio y sus instituciones conexas tuvieron en cuenta las fuentes navarras. Fue el caso de Enrique Gacto Fernández $(1969,1971,1978)^{47}$, José Martínez Gijón $(1970,1980)^{48}$, Aquilino Iglesia Ferreirós (1988 y 1990) ${ }^{49}$, Emma Montanos Ferrín $(1980)^{50}$, y Rogelio Pérez-Bustamante $(1983)^{51}$. El estellés José

${ }^{44}$ Otero Varela, A., «Las arras en el Derecho español medieval», Anuario de Historia del Derecho español, Vol. 25, 1955, pp. 189-210; «Mandas entre cónyuges», Anuario de Historia del Derecho español, Vol. 27-28, 1957-1958, pp. 399-412.

${ }^{45}$ Sierra RuIz, R., «Honor, honra e injuria en el Derecho medieval español», Anales de la Universidad de Murcia. Derecho, Vol. 23 (1964-1965), pp. 55-155; «Honor, honra e injuria en el Derecho medieval español (continuación)», Anales de la Universidad de Murcia. Derecho, Vol. 24, 1965-1966, pp. 39-216.

${ }^{46}$ Cerdá Ruiz de Funes, J., «Fueros municipales», en Mascareñas, C. E. (dir.), Nueva Enciclopedia Jurídica, X, Francisco Seix S.A., Barcelona, 1976, pp. 395-478.

${ }^{47}$ Gacto FernándeZ, E., La filiación no legítima en el Derecho Histórico español, Universidad de Sevilla, Sevilla, 1969; «La filiación ilegítima en la Historia del Derecho español», Anuario de Historia del Derecho español, Vol. 41, 1971, pp. 899-944; «El divorcio en España: evolución histórica», Historia 16, 27 (1978), pp. 19-34.

48 MARTínez GiJón, J., «Los sistemas de tutela y administración de los bienes de los menores en el Derecho local de Navarra», Anuario de Historia del Derecho español, Vol. 40, 1970, pp. 227-240; «Alimentos en favor de los ascendientes en el Derecho medieval en Navarra», Anuario de Historia del Derecho español, Vol. 50, 1980, pp. 208-222.

49 IgLeSIA Ferreirós, A., «Individuo y familia. Una historia del Derecho privado español», en Artola, M. (dir.), Enciclopedia de Historia de España, Tomo I, Alianza, Madrid, 1988, pp. 433-536; «Doctrinas e instituciones civiles: familia, matrimonio, sucesiones. La situación de los estudios de Historia del Derecho privado en España», en CLAvero, B., Grossi, P. y Tomás y VAliente, F. (a cura di), Hispania, entre derechos propios y derechos nacionales. Atti dell'Incontro di Studio Firenze-Lucca, 25, 26, 27 maggio 1989, Giuffrè, Milano, 1990, vol. 2, pp. 204-314 (la referencia al Fuero General de Navarra en p. 213).

${ }_{50}$ Montanos Ferrín, Ma E., La familia en la Alta Edad Media, EUNSA, Pamplona, 1980.

51 Pérez-Bustamante, R., Los regímenes económicos matrimoniales en la Historia del Derecho español, Universidad de Alcalá, Alcalá de Henares, 1983. 
María Lacarra, catedrático de Historia Medieval y formado también como jurista, publicó en 1981 el artículo «Sobre el matrimonio y otros arcaísmos entre vascos, navarros y aragoneses $\rangle^{52}$, todavía hoy imprescindible.

El Derecho económico-matrimonial, que podríamos considerar rama autónoma del Derecho matrimonial, fue ampliamente trabajado en su dimensión histórica por los iuspositivistas navarros de la Compilación, aspecto que trataremos en el siguiente epígrafe. Este hecho pudo ser motivo para que los historiadores del derecho navarros apenas se hubieran investigado el tema en los años sesenta, setenta y ochenta, hecha salvedad de Fernando de Arvizu Galarraga, que investigó un tema colateral, la desheredación (1976-1977, 1979 y 1982) ${ }^{53}$.

El desolador panorama iushistoriográfico navarro quedó evidenciado en el artículo «Estudios jurídicos sobre el papel de la mujer en la Baja Edad Media» (1993), de Mercedes Galán Lorda, donde trató sobre el matrimonio en las legislaciones canónica y castellana y realizó un somero repaso de la bibliografía especializada; sin embargo, no dedicó ni una sola mención a Navarra ${ }^{54}$. Más recientemente, el estado de la cuestión sobre la historiografía jurídica pirenaica relativa a la familia, obra de Serrano Daura $(2004)^{55}$, únicamente incluyó autores iuspositivistas navarros. Las investigaciones desarrolladas desde el Derecho positivo parecen ser, por otra parte, la fuente de la que se han valido los historiadores del derecho que se han ocupado - muy sucintamente- del matrimonio histórico navarro en sus manuales (José Manuel Pérez-Prendes, 1996 ${ }^{56}$, Remedios Morán Martín, 199957, y Magdalena Rodríguez Gil, 2010 58 ).

${ }^{52}$ LACARRA, J. M ${ }^{\mathrm{a}}$, «Sobre el matrimonio y otros arcaísmos entre vascos, navarros y aragoneses», Cuadernos de Historia de España, Vol. 55-56, 1981, pp. 449-455.

53 Arvizu Galarraga, F. de, «La desheredación por cinco sueldos en el Derecho altomedieval de Aragón y Navarra», Anuario de Derecho Foral, Vol. 2, 1976-1977, pp. 65-77; «Las causas de desheredación en el Derecho altomedieval de Aragón y Navarra», en Mélanges offerts à Jean Dauvillier, Centre d'Histoire juridique méridionale, Toulouse, 1979, pp. 1-14; «La réserve héréditaire dans le Droit navarrais du bas Moyen Âge», $A n$ nales du Midi, Vol. 94, 1982, pp. 91-102.

${ }^{54}$ Galán Lorda, M., «Estudios jurídicos sobre el papel de la mujer en la Baja Edad Media», Anuario Filosófico, Vol. 26/3, 1993, pp. 541-557.

55 SERrano Daura, J., «La família en la historiografia jurídica dels territoris hispànics pirenaics (s. XIX-XX)», Revista de Dret Històric Català, Vol. 4, 2004, pp. 91-120, $\mathrm{y}$, especialmente, p. 106, dedicada a la historiografía navarra.

${ }_{56}$ PÉRez-PRENDES, J. M., Interpretación histórica del Derecho, Universidad Complutense, Madrid, 1996. Reed. Historia del Derecho español, Universidad Complutense, Madrid, 1999, 2 vols.

57 Morán Martín, R., Historia del Derecho privado, penal y procesal, Madrid: UNED; Universitas, 2002, 2 vols.

${ }^{58}$ RodríGuez GiL, M., Curso de Historia, op.cit. Esta profesora publicó en $1998 \mathrm{su}$ monografía Vice Uxor. Notas sobre el concubinato en España desde la recepción del Derecho común, a partir, sobre todo, de la doctrina jurídica; apenas menciona el reino pire- 
El desolador panorama contrasta con el vigor de los estudios dedicados al pasado de la institución matrimonial en Labourd y, en menor medida, en Baja Navarra y Zuberoa, que debemos a la catedrática Maïté Lafourcade, imprescindibles para todo tipo de análisis comparativos con la Alta Navarra $^{59}$.

Entrados en el siglo XXI, asistimos a una revigorización investigadora. Rosa María Ayerbe Iríbar dio a conocer una institución contemplada en las capitulaciones matrimoniales baztanesas del siglo XVI, los auriches, consistentes en una mejora aportada por el advenedizo a la casa familiar cuando concertaba su matrimonio (2007) ${ }^{60}$. Gregorio Monreal y Roldán Jimeno analizaron la historia de la jurisdicción eclesiástica matrimonial en Navarra $(2008)^{61}$, y trazaron una visión general de la institución matrimonial en el viejo reino, observando los principales aspectos que determinaron la estructura y naturaleza de las distintas uniones conyugales. Trataron de inducir la estructura y carácter de la institución del marco externo donde se desenvolvía: condicionamientos religioso-morales y socio-económicos, vigencia espacial y temporal de las distintas formas de unión, carácter de la ordenación, autonomía de la unión conyugal frente a otras instancias institucionales, fines asignados por la sociedad y el Estado a estas uniones, etc.; atendieron, finalmente, a la tipificación del contenido del consorcio conyugal a través de la posición respectiva de los cónyuges, el valor de la potestad marital y la fidelidad, entre otros aspectos $(2010)^{62}$.

naico: Vice Uxor. Notas sobre el concubinato en España desde la recepción del Derecho común, Universidad Complutense, Madrid, 1998, pp. 112-113 (referencia al Fuero General de Navarra, 2, 4, 22.

59 Lafourcade, M., «La condition juridique de la femme en Iparralde, sous 1'Ancien Régime», Bulletin du Musée Basque, 1988, pp. 161-176; «La condición jurídica de la mujer en Iparralde bajo el Antiguo Régimen», Emakumea Euskal Herriko historian/La mujer en la historia de Euskal Herria, Colecc. Langaiak, $\mathrm{n}^{\circ}$ 12, IPES, Bilbao, 1988, pp. 59-64; Mariages en Labourd sous l'Ancien Régime. Les contrats de mariage du pays de Labourd sous le règne de Louis XVI: (étude juridique et sociologique), Universidad del País Vasco/Euskal Herriko Unibertsitatea, Bilbao, 1989; «Le Droit de la Famille en Iparralde sous l'Ancien Régime», Bulletin du Musée Basque, Vol. 167, 2006, pp. 17-38 ; LAFourcade, M. y EtcheVerry-Aïchart, J., «La transmission juridique de la maison basque», en Etxea ou la maison basque, Lauburu, SaintJean-de-Luz, 1980, $2^{\text {a }}$ ed., pp. 39-82.

${ }^{60}$ Ayerbe IríBAR, Ma R., «Los auriches en el Derecho privado del Baztán navarro (s. XVI). Datos para un concepto», Boletín de la Real Sociedad Bascongada de Amigos del País, Vol. 63/1, 2007, pp. 5-19.

${ }^{61}$ Monreal Zia, G. y Jimeno Aranguren, R., Textos, vol. 1, op.cit., pp. 683-684.

${ }^{62}$ Monreal Zia, G. y Jimeno Aranguren, R., «Naturaleza y estructura del matrimonio y otras uniones afines en el derecho histórico hispánico, con especial atención a Navarra», Príncipe de Viana, Vol. LXXI, nº 250, 2010, pp. 501-538. 
El segundo de estos autores analizó, además, el matrimonio civil o leal coniugio pretridentino $(2013)^{63}$.

\subsection{La historiografía elaborada desde el iuspositivismo}

Es en el ámbito de las aportaciones concebidas desde el iuspositivismo estricto donde, se han aportado un mayor número de contribuciones para esclarecer la historia del matrimonio. Nos referimos a los estudios que, a pesar de estar centrados en el Derecho vigente, dedican una atención especial a los antecedentes históricos. Se trata de obras elaboradas por juristas a partir de textos de carácter legal, sin tener en cuenta la praxis jurídica, es decir, sin relacionarlos con los documentos de aplicación del derecho y la jurisprudencia, que es donde se refleja la realidad de la vida jurídica del matrimonio y de las uniones sexuales permanentes. Diversos manuales de Derecho civil contienen miradas al pasado navarro, pero ninguno con la profundidad y rigor del tomo quinto del Derecho Civil español, común y foral, dedicado al Derecho de familia, de José Castán Tobeñas (1976) ${ }^{64}$. Habremos de añadir, además, el volumen tercero de los Estudios de Derecho de Familia del notario Enrique Fosar Benlloch, dedicado a la evolución histórica del matrimonio y el divorcio en España $(1985)^{65}$, con diversas referencias a las fuentes del Derecho medieval navarras.

Los trabajos de los iuspositivistas navarros están relacionados con la inserción del Derecho e instituciones forales en el sistema constitucional y codificado español, de ahí que se centren, fundamentalmente, en el análisis de los antecedentes históricos del Derecho económico-matrimonial y sucesorio vinculado al matrimonio.

Hemos apuntado en el epígrafe anterior cómo los Diccionarios de José Yanguas y Miranda fueron superados por la compilación del liberal corellano José Alonso. El que fuera ministro de Gracia y Justicia en 1841 cuando se firmó la Ley paccionada, publicó en 1848 una obra capital, la Recopilación y Comentarios de los Fueros y Leyes del antiguo reino de Navarra que han quedado vigentes después de la modificación hecha de la Ley paccionada de

${ }^{63}$ JiMENO ARANGUREN, R., «Contrarreforma y lengua: regulación jurídica y praxis en Navarra», en ANCHÚstegui, E. (coord.), Visiones poliédricas sobre la conquista de Navarra, Pamiela, Pamplona, 2013, pp. 150-154.

${ }^{64}$ Castán Tobeñas, J., Derecho Civil español, común y foral, Tomo V. Derecho de Familia. Vol. Primero. Relaciones conyugales, Reus, Madrid, 1976 ( $9^{\text {a }}$ edic., actualizada por G. García Cantero y J. M Castán Vázquez).

${ }^{65}$ Fonsar Benlloch, E., Estudios de Derecho de Familia. Tomo III. Las uniones libres. La evolución histórica del matrimonio y el divorcio en España, Bosch, Barcelona, 1985. 
16 de agosto de $1841^{66}$, profundamente deudora de Yanguas en cuanto a la identificación de las fuentes. Sus dos tomos están estructurados en ocho libros, en los que recogió las leyes del reino vigentes tras la Ley de Fueros de 1841, que transcribió total o parcialmente, y de las que hizo un comentario doctrinal de conjunto.

La identificación de las fuentes legislativas realizada por José Yanguas y Miranda (Fueros locales, General de Navarra, Amejoramientos y leyes de Cortes) y la interpretación de las mismas por parte de José Alonso, fueron el basamento de la doctrina jurídica posterior ${ }^{67}$. Lo ejemplifica el monumental trabajo del foralista estellés Victoriano Lacarra Mendiluce, Instituciones de Derecho Civil Navarro (1917 y 1932) ${ }^{68}$, encuadrador del Derecho navarro en la estructura codificada, donde son constantes las remisiones a los antecedentes legislativos históricos, fueran navarros, de Derecho civil español o de Derecho canónico. Lo mismo ocurre con el librito de Manuel Jesús Alonso Arbe, Notas sobre el sistema de sucesión universal en el derecho histórico de Navarra. El derecho de representación $(1935)^{69}$.

Hilario Yaben publicó en 1916 una obra singular, cuya trascendencia doctrinal la convierte, todavía hoy, en una referencia inexcusable para todo trabajo jurídico relativo al régimen económico-matrimonial y sucesorio navarro: Los contratos matrimoniales en Navarra y su influencia en la estabilidad de la familia ${ }^{70}$. El autor, teólogo navarro y vicario general de Sigüenza, no era jurista, aunque por su formación sacerdotal y tareas desempeñadas tenía un amplio conocimiento jurídico de la realidad estudiada, a la que se acercó desde una perspectiva sociológica. Dividió su estudio en cinco bloques: en el primero realizó unas indicaciones generales sobre los diversos sistemas de transmisión del patrimonio familiar, los diversos tipos de familia derivados de aquellos sistemas y el tipo de familia troncal surgido en Navarra de la donación del patrimonio familiar a uno de los hijos. El segundo apartado lo dedicó a las facilidades que otorgaba la legislación foral navarra para

${ }^{66}$ Alonso Ruiz, J., Recopilación y comentario de los Fueros y Leyes del Antiguo Reino de Navarra, que han quedado vigentes después de la modificación hecha por la Ley Paccionada de 16 de agosto de 1841, Saavedra y Compañía, Madrid, 1848-1849. Reed. Colecc. Biblioteca de Derecho Foral, núms. 1 y 2, Diputación Foral de Navarra, Pamplona, 1964. 2 vols.

67 Jimeno ARANGUREN, R., «Derecho civil navarro y codificación general española», Anuario de Historia del Derecho español, Vol. 82, 2012, pp. 270-271.

${ }^{68}$ LaCARra Mendiluce, V., Instituciones de Derecho Civil Navarro, Imprenta Provincial, Pamplona, 1917 y 1932, 2 vols. Reed., en un solo volumen, Diputación Foral de Navarra-Aranzadi, Pamplona, 1965.

69 Alonso Arbe, M. J., Notas sobre el sistema de sucesión universal en el derecho histórico de Navarra. El derecho de representación, Editorial Vizcaína, Bilbao, 1935.

70 YABEN Y YABEN, H., Los contratos, op.cit. 
hacer la indicada donación. El tercero lo centró en los contratos matrimoniales, indicando las diferencias existentes entre las distintas comarcas de Navarra. El cuarto dio cuenta de los resultados de esta organización familiar, y el quinto constituyó un breve estudio crítico del Derecho económico-matrimonial navarro, examinando sus ventajas y desventajas. En la determinación de los resultados y en la apreciación de las ventajas se fijó en la estabilidad de la familia troncal derivada inmediatamente de la donación propter nuptias.

El triunfo de la sublevación militar de Emilio Mola en Navarra (julio de 1936), obligó a exiliarse a diversos juristas navarros de izquierdas y nacionalistas vascos. Pocos fueron los que continuaron desarrollando estudios doctrinales en el exilio. El único que se fijó en la institución matrimonial fue el jeltzale Manuel de Irujo (1945) ${ }^{71}$, al subrayar la importancia de la casa como signo de identidad de la familia vasca.

En la Navarra franquista se produjo un relanzamiento de los estudios en el marco del frustrado Proyecto de apéndice al Código civil y del exitoso camino de la Compilación. Los foralistas acometieron estudios positivistas pertrechados de una destacada erudición histórica fundamentadora de la ley en construcción. Los años anteriores al Congreso Nacional de Derecho Civil de Zaragoza (octubre de 1946) vieron aparecer los primeros trabajos del abogado Francisco Salinas Quijada en la revista Príncipe de Viana: «Las arras en el derecho foral navarro» $(1941)^{72}$, «Conceptos y formas del matrimonio en el Derecho foral navarro» $(1943)^{73}$ y «La relación jurídica dotal en el Derecho Foral Navarro» $(1946)^{74}$. El órgano de expresión de la cultura jurídica foral del momento publicó otros dos trabajos más, uno del abogado Rafael Aizpún Tuero, «El pacto sucesorio en el Derecho civil navarro» $(1945)^{75}$, y otro del magistrado Juan Santamaría Ansa, «Retracto familiar en Navarra» (1946), en defensa de la sociedad familiar frente al individuo ${ }^{76}$.

En las casi tres décadas en las que se fraguó la Compilación del Derecho civil foral navarro asistimos a la aparición de una destacada producción doc-

${ }^{71}$ IRUjo, M. de, Instituciones jurídicas vascas, Ekin, Buenos Aires, 1945. Reed. Txalaparta, Tafalla, 2006.

72 Salinas QuiJada, F., «Las arras en el derecho foral navarro», Príncipe de Viana, Vol. II, nº 5, 1941, pp. 45-64.

73 Salinas QuiJada, F., «Conceptos y formas del matrimonio en el Derecho foral navarro», Príncipe de Viana, Vol. IV, nº 12, 1943, pp. 337-367.

74 Salinas Quijada, F., «La relación jurídica dotal en el Derecho Foral Navarro», Príncipe de Viana, Vol. VII, nº 23, 1946, pp. 309-344.

75 AizPún Tuero, R., «El pacto sucesorio en el Derecho civil navarro», Príncipe de Viana, Vol. VI, n 21, 1945, pp. 593-622. Reed. en Anuario de Derecho Aragonés, Vol. 2 , 1945, pp. 159-186.

76 Santamaría Ansa, J., «Retracto familiar en Navarra», Príncipe de Viana, Vol. VII, no 22, 1946, pp. 83-96. 
trinal marcada por un fuerte historicismo ${ }^{77}$. Una primera fase, la que discurrió desde la constitución de la Comisión compiladora hasta la redacción del Anteproyecto de Fuero Recopilado (1948-1959), estuvo marcada por las perspectivas generales del magistrado Juan Santamaría Ansa, autor de El Derecho civil de Navarra $(1955)^{78}$ y del artículo titulado «El derecho civil de Navarra» (1956) ${ }^{79}$, donde abordó aspectos como la libertad de estipulación en capítulas matrimoniales o las donaciones propter nuptias. Fueron años en los que aparecieron diversas monografías sobre Derecho sucesorio, firmadas por los prácticos del Derecho José Miguel Arriaga Sagarra $(1948)^{80}$, Eugenio Fernández Asiáin (1952) ${ }^{81}$, Joaquín Abadía Escola (1956) ${ }^{82}$, Domingo Frauca Llamas $(1956)^{83}$, y Rafael Aizpún Tuero $(1957)^{84}$.

Algunos de estos autores (Joaquín Abadía ${ }^{85}$ y Rafael Aizpún Tuero ${ }^{86}$ ) volvieron sobre estos temas en el ciclo de conferencias organizado por la

77 Vid., entre los ejemplos más significativos, García-Granero Fernández, J., «Fuero Viejo y Fuero Nuevo de Navarra», Anuario de Derecho Foral, Vol. 1, 1975, pp. 131-216. Salinas QuiJada, F., Derecho civil de Navarra. I. Introducción, Gómez, Pamplona, 1971, pp. 43-159; Elementos de Derecho civil de Navarra, Diputación Foral de Navarra, Pamplona, 1979, pp. 106-111. LóPEZ JACOISTE, J. J., «El Fuero Nuevo, un interrogante intelectual», Revista Jurídica de Navarra, Vol. 26, 1998, pp. 9-28; «El Derecho civil foral de Navarra, entre perspectivas de historia y sugerencias vivas», Anales de la Real Academia de Jurisprudencia y Legislación, Vol. 36, 2006, pp. 635-654. DoraL, J. A., «Prelación de fuentes en Derecho navarro», Anuario de Derecho Civil, Vol. 1, 1974, pp. 25-66.

${ }^{78}$ Santamaría Ansa, J., El Derecho civil de Navarra. Esquemática de su estructura y contenido, Imprenta de Felipe Gómez Alonso, Pamplona, 1955.

79 Santamaría Ansa, J., «El derecho civil de Navarra», Príncipe de Viana, Vol. XVII, nº 62, 1956, pp. 95-102.

80 Arriaga Sagarra, J. M., Libertad de testar, legitima foral y desheredación en el Derecho navarro, Consejo de Estudios de Derecho Navarro, Pamplona, 1948.

${ }^{81}$ FernándeZ Asiáin, E., Estudios de Derecho Foral Navarro. La facultad de disposición en el pacto sucesorio; La rescisión por lesión; La troncalidad; La prescripción; El usufructo de viudedad, Consejo de Estudios de Derecho Navarro, Pamplona, 1952, pp. 51-95.

${ }^{82}$ Abadía Escolá, J., Los derechos del cónyuge viudo en la legislación foral de Navarra, Consejo de Estudios de Derecho Navarro, Pamplona, 1956.

${ }^{83}$ Frauca Llamas, D., La representación sucesoria en el Derecho navarro, Universidad de Zaragoza, Zaragoza, 1956.

${ }^{84}$ Aizpún Tuero, R., La representación sucesoria en el Derecho civil de Navarra, Estudio General de Navarra, Pamplona, 1957.

85 Abadía Escolá, J., «La viudedad foral», en Curso de Derecho foral navarro. I. Derecho Privado, Estudio General de Navarra, Pamplona, 1958, pp. 193-210.

${ }^{86}$ AizPún Tuero, R., «Derecho de representación. Derecho de acrecer», en Curso de Derecho foral navarro. I. Derecho Privado, Estudio General de Navarra, Pamplona, 1958, pp. 211-227. 
Facultad de Derecho del Estudio General de Navarra entre noviembre de 1956 y abril de 1957, editadas al año siguiente. Las ponencias impartidas ahí por Rafael Aizpún Santafé ${ }^{87}$ y Juan Santamaría Ansa ${ }^{88}$ tenían un carácter general; y descendieron a cuestiones específicas Javier Nagore, que se ocupó de las capitulaciones matrimoniales ${ }^{89}$, y Jesús Luis Iribarren, que lo hizo sobre las segundas nupcias ${ }^{90}$.

A partir de 1960 se abrió una nueva etapa compiladora cuando un grupo de juristas vinculados a la Universidad de Navarra se afanaron en realizar un proyecto de compilación de manera privada. Fue una fase en la que los esfuerzos se centraron, sobre todo, en el desarrollo del cuerpo legal, sin que, por el momento, se dieran a las prensas estudios doctrinales, hecha salvedad de la monografía de José Arregui Gil dedicada a la fidelidad vidual (1968) ${ }^{91}$ y un nuevo artículo de Javier Nagore sobre capitulaciones matrimoniales ${ }^{92}$. Al margen del grupo compilador, aunque estrechamente vinculado a él, el civilista aragonés José Luis Lacruz Berdejo elaboró un trabajo sobre la viudedad foral navarra $(1966)^{93}$ y trató sobre el régimen matrimonial navarro histórico en su estudio de los fueros de Aragón (1946) ${ }^{94}$.

La propuesta de los compiladores se concretó en la denominada Recopilación privada, que fue publicada en $1971^{95}$. Fue propósito de sus artífices «recoger simplemente el Derecho Civil vigente en Navarra, actualizando sus antiguas leyes y costumbres, eliminando lo que del Derecho Romano había

87 Aizpún SANTAFÉ, R., «Ideas generales de las instituciones del Derecho civil navarro», en Curso de Derecho foral navarro. I. Derecho Privado, Estudio General de Navarra, Pamplona, 1958, pp. 1-26.

${ }^{8}$ Santamaría AnSa, J., «Derecho de familia», en Curso de Derecho foral navarro. I. Derecho Privado, Estudio General de Navarra, Pamplona, 1958, pp. 107-124.

89 Nagore YÁrnoz, J. J., «Capitulaciones matrimoniales», en Curso de Derecho foral navarro. I. Derecho Privado, Estudio General de Navarra, Pamplona, 1958, pp. 141-177.

${ }^{90}$ IrIBARREn, J. L., «Segundas nupcias», en Curso de Derecho foral navarro. I. Derecho Privado, Estudio General de Navarra, Pamplona, 1958, pp. 127-139.

${ }_{91}$ Arregui GiL, J., La fidelidad vidual en el Derecho privado de Navarra, Institución Príncipe de Viana, Pamplona, 1968.

92 NAGORE YÁrnOZ, J. J., «Doctrina actual sobre las capitulaciones matrimoniales en Derechos Común y Foral», en Estudios de Derecho Civil en honor del profesor Castán Tobeñas, Universidad de Navarra, Pamplona, 1969, vol. 4, pp. 505-550.

93 Lacruz Berdejo, J. L., «Cuestiones fundamentales de la viudedad foral de Navarra», Príncipe de Viana, Vol. XXVII, n 104-105, 1966, pp. 245-266. Reed. Revista Jurídica de Navarra, Vol. 8, 1989, pp. 13-30.

94 Lacruz Berdejo, J. L., «El régimen matrimonial de los fueros de Aragón», Anuario de Derecho Aragonés, Vol. 3, 1946, pp. 17-153. Reed. en su obra Estudios de Derecho Privado Común y Foral, Cometa, Zaragoza, 1992, vol. 3, pp. 191-306.

95 García-Granero Fernández, J. et alii, Derecho Foral de Navarra, op.cit. 
caído en desuso, adaptando el antiguo Derecho a las exigencias de la vida y de la ciencia jurídica actuales $\rangle^{96}$. La segunda parte de la obra consistió en una serie de «notas» aclaratorias del fundamento histórico legal, doctrinal o jurisprudencial de cada una de las leyes, de ahí que las páginas de su libro constituyan un punto de partida obligado para conocer los antecedentes históricos del Fuero Nuevo.

Promulgada la Compilación civil foral de Navarra en 1973, los trabajos posteriores de los artífices del Fuero Nuevo desgranaron con amplia erudición y fuerte positivismo las fuentes históricas en las que se habían basado al elaborar las leyes de esta fuente. Los autores más prolíficos fueron Juan García-Granero ${ }^{97}$ y Francisco Salinas Quijada ${ }^{98}$, Javier Nago-

96 IBÍDEM, pp. 12-13.

97 García-Granero Fernández, J., «Fuero General de Navarra 4, 2, 3. El cónyuge viudo que tiene fealdat ¿puede enajenar en caso de necesidad?», Anuario de Derecho Civil, Vol. 27, 1974, pp. 91-268; «Domna et domina, potens et usufructuaria», Anuario de Derecho Foral, Vol. 2, 1976-1977, pp. 97-322; «Anotaciones de un ius foralista sobre el libro de un lingüista: «Registro del Concejo de Olite», de Ricardo Ciérvide», Anuario de Derecho Foral, Vol. 2, 1976-1977, pp. 337-391. Es autor, asimismo, de comentarios a diversas leyes del Fuero Nuevo, en la obra dirigida por Albaladejo, M., Comentarios al Código civil Compilaciones forales. Tomo XXXVI, vol. $1^{\circ}$. Leyes 42 a 81 de la Compilación o Fuero Nuevo de Navarra, EDERSA, Madrid, 1990: «Comentario al Título II: De las entidades y sujetos colectivos sin personalidad jurídica; leyes capacidad de los cónyuges; leyes 48 y 49», pp. 89-119; «Comentario al Título IV: De la capacidad de los cónyuges; leyes 53 a 62», pp. 136-247; «Comentario al Título VII: De los principios fundamentales del régimen de bienes de la familia; leyes 75 a 77», pp. 403-424; «Comentario al Título VIII: De las capitulaciones matrimoniales; leyes 78 a 81», pp. 425-499; "Comentario al Título IX: Del régimen de bienes en el matrimonio; leyes 82-104», pp. 1-361; «Comentario al Título X: Del régimen de bienes en segundas o posteriores nupcias; leyes 105-111», pp. 362-447; y «Comentario al Título XI: De las donaciones propter nuptias; leyes 112-118», pp. 448-505.

98 Salinas Quijada, F., Derecho civil de Navarra. I. Introducción, Gómez, Pamplona, 1971; Derecho civil de Navarra. II. Derecho de las personas. Derecho de las cosas (De los bienes en general. Del dominio. De la posesión), Gómez, Pamplona, 1972; Derecho civil de Navarra. V. Derecho de Familia. Volumen 1. Organización de la familia, Gómez, Pamplona, 1975; Derecho civil de Navarra. V. Derecho de Familia. Volumen 2. Del régimen de bienes en la familia y en el matrimonio, Gómez, Pamplona, 1975; Derecho civil de Navarra. VI. De las donaciones y sucesiones. Volumen 1. De las donaciones, sucesión contractual, sucesión testamentaria: naturaleza, formas y contenido, Gómez, Pamplona, 1977; Derecho civil de Navarra. VI. De las donaciones y sucesiones. Volumen 2. Sucesión testamentaria (conclusión), sucesión legal, constitución, cesión y partición de la herencia, Gómez, Pamplona, 1977; «La familia foral navarra», Anuario de Derecho Foral, Vol. 1, 1975, pp. 217-244; Elementos de Derecho civil de Navarra, Diputación Foral de Navarra, Pamplona, 1979; «El Derecho Civil en el Fuero de San Sebastián y sus relaciones con el Derecho Civil en los Fueros Navarros», en El Fuero de San Sebastián y su época, Eusko Ikaskuntza, San Sebastián, 1982, pp. 301-378; Estudio comparativo del Derecho ayalés y 
re ${ }^{99}$, Álvaro d'Ors ${ }^{100}$ y José Arregui Gil ${ }^{101}$. Son estudios de síntesis, desarrollados, en buena medida, a partir del rastreo de los antecedentes legislativos y una selección de capitulaciones matrimoniales que tuvieron en cuenta al acometer la Compilación ${ }^{102}$.

Otros civilistas también se ocuparon de los antecedentes del Derecho civil foral actual. Fueron, en concreto, José Castán Tobeñas ${ }^{103}$, José Luis Lacruz Berdejo, Joaquín Rams Albesa y Francisco de Asís Sancho Rebulli-

navarro, Diputación Foral de Álava, Vitoria, 1983; «La indisolubilidad del matrimonio en el Derecho Civil navarro», Ius Canonicum, Vol. XXIV/47, 1984, pp. 387-431; Examen elemental de las Instituciones de Derecho Civil Foral de Navarra, Gobierno de Navarra, Pamplona, 1985; «El hijo no matrimonial en el Derecho civil foral de Navarra», en Libro homenaje a Juan Berchmans Vallet de Goytisolo, Junta de Decanos de los Colegios Notariales de España-Consejo General del Notariado, Madrid, 1988, vol. 2, pp. 697-762; Compendio de Derecho civil navarro, Gobierno de Navarra, Pamplona, 1991.

99 NAgOre YÁrnOZ, J. J., «Comentario al Título XIV: Del acogimiento a la casa y de las dotaciones; leyes 131-136», en Albaladejo, M. (dir.), Comentarios al Código civil Compilaciones forales. Tomo XXXVI, vol. $2^{\circ}$. Leyes 82 a 147 de la Compilación o Fuero Nuevo de Navarra, EDERSA, Madrid, 1995, pp. 546-567; «Comentario al Título X: De las limitaciones a la libertad de disponer. Capítulo II. De la legítima; leyes 267-271», en Albaladejo, M. (dir.), Comentarios al Código civil Compilaciones forales. Tomo XXXVII, vol. $2^{\circ}$. Leyes 253 a 345 de la Compilación o Fuero Nuevo de Navarra, EDERSA, Madrid, 2001, pp. 163-215.

100 D’Ors, Á. y Durán Rivacoba, R., «Comentario al Título XII: De la dote y de las arras; leyes 119-127», en AlbaladeJo, M. (dir.), Comentarios al Código civil Compilaciones forales. Tomo XXXVI, vol. $2^{\circ}$. Leyes 82 a 147 de la Compilación o Fuero Nuevo de Navarra, EDERSA, Madrid, 1995, pp. 506-524.

101 ARregui GIL, J., «Reflexiones sobre la fidelidad vidual navarra (fealdat)», Revista Jurídica de Navarra, Vol. 15, 1993, pp. 15-26; «Comentario al Título X: De las limitaciones a la libertad de disponer. Capítulo I. Del usufructo de fidelidad; leyes 253-266», en ALBALADEJo, M. (dir.), Comentarios al Código civil Compilaciones forales. Tomo XXXVII, vol. $2^{\circ}$. Leyes 253 a 345 de la Compilación o Fuero Nuevo de Navarra, EDERSA, Madrid, 2001, pp. 1-162; «Comentario al Título X: De las limitaciones a la libertad de disponer. Capítulo III. Derechos de los hijos de anterior matrimonio; leyes 272 y 273», en ALBALADEJO, M. (dir.), Comentarios al Código civil Compilaciones forales. Tomo XXXVII, vol. $2^{\circ}$. Leyes 253 a 345 de la Compilación o Fuero Nuevo de Navarra, EDERSA, Madrid, 2001, pp. 215-234.

102 A los comentarios de los compiladores habremos de sumar los realizados en esa obra por NANCLARES VALLe, J., «Comentario al Título X: De las limitaciones a la libertad de disponer. Capítulo IV. De la reserva del bínubo; leyes 274-278», en AlBALADEJo, M. (dir.), Comentarios al Código civil Compilaciones forales. Tomo XXXVII, vol. $2^{\circ}$. Leyes 253 a 345 de la Compilación o Fuero Nuevo de Navarra, EDERSA, Madrid, 2001, pp. 235-293; «Comentario al Título X: De las limitaciones a la libertad de disponer. Capítulo V. De la reversión de bienes; leyes 279-280», en AlbaladeJo, M. (dir.), Comentarios al Código civil Compilaciones forales. Tomo XXXVII, vol. $2^{\circ}$. Leyes 253 a 345 de la Compilación o Fuero Nuevo de Navarra, EDERSA, Madrid, 2001, pp. 294-320.

103 Castán Tobeñas, J., Derecho Civil español, op.cit. 
da $^{104}$. Gabriel García Cantero se ocupó de analizar el Derecho civil en el Fuero de San Sebastián ${ }^{105}$, y el notario Francisco Javier Octavio de Toledo desarrolló una peculiar monografía dedicada a las capitulaciones matrimoniales y testamento de doña Blanca de Navarra ${ }^{106}$.

La siguiente generación de juristas no ha mostrado interés por la historia, y construye su doctrina generalmente centrándose en el Derecho vigente. Si en alguna ocasión apuntan alguna fuente iushistórica, no pasa de ser mero apunte erudito de escaso valor, tomado de segunda, tercera o cuarta mano ${ }^{107}$.

\subsection{La historiografía canónica}

Gracias a los estudios de Federico R. Aznar Gil conocemos muy bien el Derecho canónico matrimonial de las diócesis peninsulares extendidas en el reino de Navarra. Este autor realizó un análisis concienzudo de las fuentes pretridentinas conciliares y sinodales hispánicas. Se acercó a la institución matrimonial desde meritorias perspectivas generales (1982, 1989, 2001, $2002)^{108}$, y profundizó en aspectos concretos como el consentimiento paterno o familiar $(1995)^{109}$, las amonestaciones o proclamas matrimoniales $(1999)^{110}$,

${ }^{104}$ Lacruz Berdejo, J. L. y Rams Albesa, J., «La comunidad matrimonial de conquistas en Navarra», Revista Jurídica de Navarra, Vol. 6, 1988, pp. 11-34; LACRUZ BERDEJO, J. L. y Sancho Rebullida, F. de A., Derecho de Familia, Bosch, Barcelona, 1974, 2 vols.; IBIDDEM, «Beneficios viduales derivados del régimen matrimonial en Aragón, Navarra y Vizcaya», en Elementos de Derecho Civil, Bosch, Barcelona, 2009, vol. 4, pp. 550-558.

105 García Cantero, G., «El derecho civil en el Fuero de San Sebastián», en El Fuero de San Sebastián y su época, Eusko Ikaskuntza, San Sebastián, 1982, pp. 379-396.

106 Octavio de Toledo Eugui, F. J., Poderes, capitulaciones matrimoniales y testamento de la reina Doña Blanca Primera de Navarra y su contrafuero: historia y derecho vigente, Sancho el Fuerte Publicaciones, Pamplona, 2013.

107 Caso, por ejemplo, del artículo de De Pablo Contreras, P., «Nuevas nupcias y vida marital como causas de extinción del usufructo de fidelidad navarro», Revista Jurídica de Navarra, Vol. 1 (enero-junio 1986), pp. 121-139.

108 AzNar GiL, F. R., Concilios provinciales y Sínodos de Zaragoza de 1215 a 1563, Caja de Ahorros de la Inmaculada, Zaragoza, 1982; La introducción del matrimonio cristiano en Indias: aportación canónica (siglo XVI), Universidad Pontificia de Salamanca, Salamanca, 1985; Derecho Matrimonial Canónico. Vol I. Cánones 1055-1094, Universidad Pontifica de Salamanca, Salamanca, 2001; Derecho Matrimonial Canónico. Vol II. Cánones 1057; 1095-1107, Universidad Pontifica de Salamanca, Salamanca, 2002; Derecho Matrimonial Canónico. Vol III. Cánones 1108-1165, Universidad Pontifica de Salamanca, Salamanca, 2003.

109 AzNAR GIL, F. R., «El consentimiento paterno o familiar para el matrimonio en la legislación eclesiástica ibérica bajomedieval (siglos XII-XVI)», Rivista Internazionale di Diritto Comune, Vol. 6, 1995, pp. 127-151.

110 AZNAR GIL, F. R., «Las amonestaciones o proclamas matrimoniales en los sínodos ibéricos medievales (siglos XIII-XVI)», en FERnÁnDEZ, J. J. (ed.), Sínodos diocesanos y 
los matrimonios clandestinos $(2003)^{111}$, los clérigos concubinarios $(1998)^{112}$, y los hijos ilegítimos (1993) $)^{113}$.

El medievalista Juan Robert Muro Abad profundizó, a través del análisis de las constituciones sinodales, en la realidad de los clérigos concubinarios bajomedievales de la diócesis de Calahorra (1993) ${ }^{114}$. Y los modernistas Antonio Irigoyen López y Francisco J. Crespo Sánchez se adentraron en los sínodos pretridentinos de Calahorra y Pamplona para analizar la regulación eclesiástica de la sociedad rural (2012); no perseguían esclarecer categorías jurídicas o efectuar análisis de Derecho, sino contribuir al conocimiento de la sociedad rural, de ahí que la institución matrimonial apenas cobre protagonismo a pesar de la riqueza de los cánones calagurritanos sobre la materia ${ }^{115}$.

Las constituciones sinodales de las diócesis de Bayona y conciliares de la provincia eclesiástica de Auch, y las sinodales de la diócesis de Dax, fueron publicadas y analizadas por Víctor-Pierre Dubarat (1892 y 1897-1898) ${ }^{116}$ y Antoine Degert (1898) $)^{117}$, respectivamente, aunque estos trabajos no descendieron a describir la institución matrimonial en estas fuentes.

Falta, para el período posterior de Trento, un estudio sobre el matrimonio en las Constituciones sinodales de Pamplona de 1590, laguna historiográfica que no existe para la diócesis de Calahorra, al menos en lo concerniente al

legislación particular. Estudios históricos en honor al Dr. D. Francisco Cantelar Rodríguez, Universidad Pontificia de Salamanca, Salamanca, 1999, pp. 135-160.

111 AzNAR GiL, F. R., «Penas y sanciones contra los matrimonios clandestinos en la Península Ibérica en la Baja Edad Media», Revista de Estudios Histórico-Jurídicos, Vol. 25, 2003, pp. 189-230.

112 AzNAR GIL, F. R., «Penas y sanciones contra los clérigos concubinarios en la Península Ibérica (s. XIII-XVI)», Studia Gratiana, Vol. 29, 1998, pp. 501-520.

113 AzNar Git, F. R., «Los ilegítimos en la Península Ibérica durante la Baja Edad Media», Revista Española de Derecho Canónico, Vol. 20, 1993, pp. 9-48.

${ }^{114}$ Muro Abad, J. R., «La castidad del clero bajomedieval en la Diócesis de Calahorra», Historia. Instituciones. Documentos, Vol. 20, 1993, pp. 261-282.

115 Irigoyen LóPez, A. y Crespo SÁnchez, F. J., «Sínodos pretridentinos de Calahorra y Pamplona: La Iglesia y la regulación de la sociedad campesina», en PÉREZ Álvarez, M. J. y Rubio Pérez, L. M. (eds.), Campo y campesinos en la España Moderna. Culturas politicas en el mundo hispano, Fundación Española de de Historia Moderna, Madrid, 2012, pp. 1327-1336.

116 Dubarat, Victor-Pierre, Statuts synodaux du Diocèse de Bayonne de 1533, Impr. Vignancour, Pau, 1892; «Les Constitutions provinciales de la province ecclésiastique d'Auch, 1290-1315, et les statuts du chapitre de Bayonne au XIV ${ }^{\mathrm{e}}$ siècle», Bulletin de la Société des sciences, lettres et arts de Pau, 2e série, Vol. 27, 1897-1898, pp. 113-200. Reed. Les Constitutions provinciales de la province ecclésiastique d'Auch, 1290-1315, et les statuts du chapitre de Bayonne au XIVe siècle, Vve Léon Ribaut, Pau, 1899.

117 Degert, A., Constitutions synodales de l'ancien diocèse de Dax, Imprimerie-Reliure H. Labèque, Dax, 1898. 
sínodo de 1698, de Pedro de Lepe, al que dedicó su tesis doctoral Ignacio Granado Hijelmo, publicada en forma de amplio extracto en 2010-2011 ${ }^{118}$. Continuamos, por tanto, anclados en un retraso historiográfico de más de medio siglo respecto de los trabajos desarrollados en otros territorios hispánicos como Galicia ${ }^{119}$ o Valencia ${ }^{120}$.

Carecemos, asimismo, de una historiografía relativa a las fuentes conciliares y sinodales contemporáneas, hecha salvedad de la monografía de Fernando Crovetto sobre el Concilio provincial de Zaragoza de 1908, editada en $2009^{121}$.

Por otra parte, la praxis del Derecho canónico matrimonial navarra apenas ha sido trabajada desde una perspectiva iuscanónica. Contamos, en primer lugar, con el trabajo inacabado de José María Jimeno Jurío sobre la evolución de la institución matrimonial y el celibato en el Occidente europeo y en Navarra. Realizado a finales de los años sesenta cuando era sacerdote, se enmarca en la línea renovadora del Concilio Vaticano II. Fue publicado en el año 2004 precedido de un análisis introductorio ${ }^{122}$. Una vez secularizado, este historiador reconstruyó, a partir de los fondos de la sección de Protocolos notariales del Archivo General de Navarra, la «Política matrimonial familiar del Doctor Navarro (1556-1567)» (1986), dando cuenta del diseño matrimonial del círculo familiar del célebre canonista, cuyo objetivo pasaba por conservar y aumentar la casa y la hacienda ${ }^{123}$. Más recientemente, Roldán Jimeno analizó las instituciones del concubinato y del matrimonio de los clérigos medievales navarros $(2011)^{124}$.

118 Granado Hijelmo, I., «El sínodo diocesano del obispo Lepe: estudio jurídico. De synodo diocesana episcopi lepei, iuris Studium», Cuadernos Doctorales de la Facultad de Derecho Canónico, Vol. 24/1, 2010-2011, pp. 11-92.

119 Pedret Casado, P., El matrimonio en las constituciones sinodales de Galicia desde el Concilio de Trento, especialmente en las del arzobispo de Santiago, D. Francisco Blanco, Universidad de Santiago de Compostela, Santiago de Compostela, 1943.

120 Sebastián Iranzo, V., La institución matrimonial en el derecho sinodal valentino. Estudio del matrimonio en los sínodos y concilios provinciales celebrados en Valencia, Institución Alfonso el Magnánimo, Valencia, 1957.

${ }^{121}$ Crovetto, F., El Concilio Provincial de Zaragoza de 1908. La reacción de los obispos ante el proceso de secularización, Edusc, Roma, 2009.

${ }_{122}$ Jimeno ARAnguren, R., «Historiografía posconciliar navarra en torno a la evolución de la institución matrimonial y del celibato en el Occidente europeo y en Navarra: análisis y edición de un trabajo inédito de J. Ma Jimeno Jurío», Anales de Derecho. Colección Huarte de San Juan, Vol. 5, 2004, pp. 125-159.

${ }^{123}$ Jimeno JuRío, J. Ma , «Política matrimonial familiar del Doctor Navarro (15561567)», Príncipe de Viana, Vol. XLVII, n 179, 1986, pp. 641-661. Reed. en Navarra en época moderna y contemporánea, Colecc. Obras completas de José María Jimeno Jurío, $\mathrm{n}^{\text {o }}$ 10, Pamiela-Udalbide-Euskara Kultur Elkargoa, Pamplona, 2007, pp. 37-66.

124 Jimeno Aranguren, R., "Concubinato, matrimonio y adulterio de los clérigos: notas sobre la regulación jurídica y praxis en la Navarra medieval», Anuario de Historia del Derecho español, Vol. 81, 2011, pp. 543-574. 
La tesis doctoral de Alejandro Lizarraga Artola, La praxis acerca del matrimonio en la diócesis de Pamplona antes del Concilio de Trento (15011560) (1991) ${ }^{125}$ continúa inédita, aunque se extractó en un amplio artículo. Enmarcó la praxis jurídica diocesana pamplonesa pretridentina en la legislación y doctrina matrimoniales, a partir de un rastreo concienzudo de la documentación procesal de los Archivos Diocesano, Catedralicio y General de Navarra. Lizarraga probó que la inmensa mayoría de las causas matrimoniales vistas en la curia diocesana se iniciaban por una demanda de validez del matrimonio presentada por una de las partes; frente a las demandas postridentinas, que solían centrarse en la nulidad del matrimonio, siendo estos últimos generados frecuentemente con motivo de impotencia física o por falta de libertad. Otros procesos matrimoniales posteriores a 1564 suelen versar sobre esponsales o cumplimiento de promesa de matrimonio, y sobre separación matrimonial. Observó, asimismo, la incidencia inmediata que tuvo este Concilio a través de los pleitos relativos a los matrimonios clandestinos, que fueron duramente castigados.

Algunos de estos procesos judiciales habían sido estudiados previamente por José María Satrustegi, en concreto, los relativos a la ruptura de las promesas de matrimonio que contenían fragmentos de testimonios en euskera. Este académico de la Lengua Vasca quería dar a conocer y analizar lingüísticamente estos testimonios, que a nosotros nos sirven para reconstruir la institución matrimonial anterior a Trento ${ }^{126}$.

En cuanto a la doctrina canónica medieval y moderna relativa al matrimonio, ya hemos apuntado que carecemos de una doctrina específicamente navarra, hecha salvedad, de alguna manera. Cuatro eminentes eclesiásticos de nuestra tierra desarrollaron sus estudios desde sedes eclesiásticas o académicas foráneas. Se trata del teólogo Sancho de Carranza de Miranda, y de los canonistas Martín de Azpilcueta, Bartolomé de Carranza de Miranda y Juan de Palafox y Mendoza. Sobreabundan los estudios en torno a estos autores, sobre todo de los tres últimos. Ana Azanza Elío realizó una síntesis del pensamiento de los cuatro y recogió la bibliografía más destacada

${ }^{125}$ Lizarraga Artola, A., «La praxis», op.cit., pp. 331-392.

126 SAtrústegui, J. Ma , «Promesa matrimonial del año 1574 en euskera en Uterga», Fontes Linguae Vasconum, Vol. IX/25, 1977, pp. 109-114; "Anotaciones al proceso matrimonial vasco de Esparza de Galar (1559)», Fontes Linguae Vasconum, Vol. IX/26, 1977, pp. 259-269; «Contribución al fondo de textos antiguos vascos», Anuario del Seminario de Filología Vasca Julio de Urquijo, Vol. 12-13, 1978-1979, pp. 227-235; «Nueva contribución al fondo de textos antiguos vascos», Anuario del Seminario de Filología Vasca Julio de Urquijo, Vol. 15, 1981, pp. 77-91; Euskal testu zaharrak, Euskaltzaindia, Pamplona, 1987; «El euskera en Tierra Estella», Euskera, 36/2, 1991, pp. 93-124; «Cuatro promesas matrimoniales inéditas en euskera del siglo XVI», Fontes Linguae Vasconum, Vol. XXIV/59, 1992, pp. 55-69. 
$(1997)^{127}$. En cuanto al Doctor Navarro, son cita obligada los trabajos monográficos dedicados al análisis de su doctrina matrimonial elaborados por Ignacio Bañares (1988) ${ }^{128}$, Luis Manuel García (1988) ${ }^{129}$ y María Isabel Muguruza Roca (2011) - desarrollado en este caso desde una perspectiva de historia de género ${ }^{130}$-; y la doctrina de Juan de Palafox ha sido trabajada por Josep-Ignasi Saranyana $(2010)^{131}$.

Los dos tratados sobre el matrimonio del jesuita Joaquín de Lizarraga, analizados por Ana Zabalza Seguín (2005) ${ }^{132}$, no obedecen a una reflexión jurídico-canónica. Uno de ellos, publicado por Apecechea ${ }^{133}$, es un comentario teológico-pastoral sobre el sacramento matrimonial, distribuido en ocho sermones. Tampoco tienen un carácter jurídico las consideraciones vertidas por el insigne civilista y canonista José Goya y Muniáin (Azanza, 1756-Sevilla, 1807) en su Diálogo compuesto en 1790 para su hermano mayor con el fin de que este se santificase a través de los quehaceres domésticos ${ }^{134}$.

\subsection{La historiografia social y de las mentalidades}

Navarra contó con un temprano análisis social del régimen económicomatrimonial, el estudio ya aludido de Hilario Yaben publicado en 1916, que

127 AzanZa Elío, A., Diccionario de pensadores. I. Pensadores navarros, siglos XII$X X$, Eunate, Pamplona, 1997.

128 BAÑARES, J. I., «Edad y discreción de juicio en el matrimonio entre impúberes: una respuesta del Doctor Navarro», Estudios sobre el Doctor Navarro en el IV Centenario de la muerte de Martín de Azpilcueta, EUNSA-Gobierno de Navarra, Pamplona, 1988, pp. 283-291.

129 García, L. M., «La significación matrimonial en la doctrina de Martín de Azpilcueta», Estudios sobre el Doctor Navarro en el IV Centenario de la muerte de Martín de Azpilcueta, EUNSA-Gobierno de Navarra, Pamplona, 1988, pp. 265-282.

130 Muguruza RocA, M ${ }^{\mathrm{a}}$ I., "Género y sexo en los confesionales de la contrarreforma. Los pecados de las mujeres en el Manual de confesiones y penitentes de Martín de Azpilcueta», Estudios humanísticos. Filología, Vol. 33, 2011, pp. 195-218.

131 Saranyana, J. I., «Cómo vio Palafox a las mujeres», en Fernández Gracia, R. (coord.), Varia palafoxiana. Doce estudios en torno a don Juan de Palafox y Mendoza, Gobierno de Navarra, Pamplona, 2010, pp. 299-301.

132 Zabalza Seguín, A., «El tratado sobre el matrimonio de Joaquín de Lizarraga (1782)», en Arellano, I. y UsunÁRIZ, J. Ma (eds.), El matrimonio en Europa y en el mundo hispánico: siglos XVI y XVII, Visor, Madrid, 2005, pp. 211-223.

133 APECECheA Perurena, J., «Tratado sobre el matrimonio», op.cit.

134 Transcrito y analizado por GoÑI GazTAMBIDE, J., «El «Diálogo» de José Goya y Muniáin», Príncipe de Viana, Vol. XXXII, n 122-123 (1971), pp. 77-115. Reed. Homenaje a José Goñi Gaztambide, II. Príncipe de Viana, Vol. LXXI, nº 251 (2010), pp. $1077-$ 1108. 
contiene, implícitos o explícitos, los embriones para el ulterior desarrollo de la historiografía social y de las mentalidades ${ }^{135}$.

Entre las múltiples tendencias historiográficas europeas del siglo XX en la investigación de la historia de la familia y del matrimonio ${ }^{136}$, destaca la abierta por la tercera generación de la Escuela de Annales (1969-1989), consagrada a la historia social y de las mentalidades. Esta importante línea de investigación en torno al matrimonio desde una apuesta historiográfica de inequívoca vocación multidisciplinar ${ }^{137}$ ha contribuido a enriquecer la historiografía jurídica, de ahí que sea pertinente apuntar los rasgos fundamentales de esta línea de investigación. Esta corriente historiográfica se centró en la investigación de la vida cotidiana, el inconsciente, las emociones, las creencias populares, los imaginarios sociales, las formas de conciencia personal y colectiva, o las estructuras ideológicas, entre otros aspectos, de ahí que, los estudiosos hayan hecho aflorar, al trabajar la historia del matrimonio, aspectos como las estrategias familiares, la conflictividad, el papel del Estado y de la Iglesia en la definición del matrimonio, el amor, el sexo... a través del análisis de un amplio y variado conjunto de fuentes jurisprudenciales, notariales -sobre todo capitulaciones matrimoniales-, económicas, demográficas y de otra índole. Es conocida influencia de esta Escuela en España ${ }^{138}$.

La metodología de la tercera generación de Annales tuvo recepción temprana en Navarra con el ya mencionado estudio de José María Jimeno Jurío de finales de los años sesenta sobre la institución matrimonial y el celibato en Navarra ${ }^{139}$.

135 YABEN Y YABEN, H., Los contratos, op.cit.

${ }^{136}$ CASEY, J., «Familia y tendencias historiográficas en el siglo XX: introducción general sobre Europa», en Mesquita Samara, E. de, Lozano Armendares, T. y Chacón JiMÉNEZ, F. (coords.), Sin distancias. Familia y tendencias historiográficas en el siglo XX, Universidad de Murcia, Murcia, 2002, pp. 25-46. Casey es, por otra parte, autor de una monografía generalista imprescindible, Historia de la familia, Espasa-Calpe, Madrid, 1990.

137 Vid. las consideraciones amplias sobre el tema en Burguière, A., L'École des Annales. Une histoire intellectuelle, Odile Jacob, Paris, 2006.

${ }^{138}$ Para el estado de la cuestión de la historia del matrimonio y de la familia en España remitimos al trabajo de Francisco CHACóN JIMÉNEZ, «Una aproximación a la historia de la familia en España a través de las fuentes bibliográficas durante el siglo XX», en MESQuita Samara, E. de, Lozano Armendares, T. y Chacón Jiménez, F. (coords.), Sin distancias. Familia y tendencias historiográficas en el siglo XX, Universidad de Murcia, Murcia, 2002, pp. 63-84; y a los diferentes análisis regionales recogidos en el libro coordinado por GARCíA GonzÁLEZ, F., La Historia de la familia en la Península Ibérica. Balance regional y perspectivas. Homenaje a Peter Laslett, Universidad de Castilla-La Mancha, Cuenca, 2008.

139 Analizado y publicado por JiMENO ARANGUREN, R., «Historiografía posconciliar», op.cit., pp. 125-159. 
Una década después aparecieron las primeras obras que analizaron desde al historiografía social diversos aspectos sobre el matrimonio histórico navarro: Los bastardos de la casa real navarra (1979), de Fernando Videgáin Agós, recorrió minuciosamente la bastardía de los reyes navarros medievales ${ }^{140}$. Y el erudito baztanés Eulogio Zudaire Eulate analizó el quitamiento de dote en razón de matrimonio en el valle de Baztan (1979) ${ }^{141}$.

Algunos investigadores de los años ochenta recurrieron a las fuentes del derecho navarras para analizar la violación, el rapto y el adulterio en el Fuero General -caso del médico e historiador pamplonés Luis del Campo Jesús $(1985)^{142}$, , o los conceptos «Adúltero», «Concupinario», «Mujer», «Criatura de echada», «Matrimonio», «Puta» y «Vecindad», que José María Jimeno Jurío elaboró de los libros de actas municipales de la villa de Tafalla $(1987)^{143}$.

Pero fueron los años noventa y los actuales dos mil en los que se asistió a una recepción masiva de la historia social y de las mentalidades aplicada a investigaciones desarrolladas desde diversas universidades, centradas, fundamentalmente, en dos grandes temas: las estrategias matrimoniales -en gran medida motivadas por el sistema de heredero único-, y la conflictividad del matrimonio. El interés académico sobre el tema se ha concretado en la celebración de diversos congresos monográficos sobre la materia, siendo el primero de ellos las «V Jornadas de Historia Local. La familia en Euskal Herria: Parentesco, trabajo, propiedad... a través de la Historia», de Eusko Ikaskunt-

140 VIDEGÁIN Agós, F., Los bastardos de la casa real navarra, Ediciones y Libros, Pamplona, 1979.

141 Zudaire Huarte, E., «Quitamiento de dote en razón de matrimonio (Valle de Baztán)», Cuadernos de Etnología y Etnografia de Navarra, Vol. XI, no 32 (1979), pp. 249-276.

${ }^{142}$ Del Campo Jesús, L., «Violación, rapto y adulterio en el Fuero General de Navarra», Cuadernos de Etnología y Etnografía de Navarra, Vol. XVII, no 45 (1985), pp. $17-$ 36. Más recientemente, C. LALIENA CORBERA regresó sobre esos conceptos y, en general, sobre el matrimonio en el Fuero General en «Honor, vergüenza y estatus en las familias serviles del Pirineo Central en la Edad Media», DE LA Iglesia DuARTe, J. I. (coord.), La familia en la Edad Media. XI Semana de Estudios Medievales. Nájera, del 31 de julio al 4 de agosto de 2000, Instituto de Estudios Riojanos, Logroño, 2001, pp. 189-197.

143 Jimeno Jurío, J. Ma , Vocabulario histórico Navarro. Villa de Tafalla, Altaffaylla Kultur taldea, Tafalla, 1987. Reed. en Merindad de Olite. I. Historia de Tafalla, Colecc. Obras completas de José María Jimeno Jurío, n 18 , Pamiela-Udalbide-Euskara Kultur Elkargoa, Pamplona, 2009, pp. 147-368. Añádase a estas voces la de «Matrimonio. Etnografía», firmada por este autor en la Gran Enciclopedia Navarra, Caja de Ahorros de Navarra, Pamplona, 1990, vol. 7, pp. 253-254. Reed. «Voces para un Diccionario etnográfico y folklórico», Etnografia histórica al airico de la tierra, Colecc. Obras completas de José María Jimeno Jurío, $\mathrm{n}^{\circ}$ 50, Pamiela-Udalbide-Euskara Kultur Elkargoa, Pamplona, 2010, pp. 379-381. 
za (1997) ${ }^{144}$, a los que siguieron el Simposio «Familia y cambio social en Navarra y el País Vasco. Siglos XIII al XX» organizado por el Instituto de Ciencias para la Familia de la Universidad de Navarra $(2002)^{145}$, y los dos Seminarios de Historia del Derecho de Navarra desarrollados desde el área de Historia del Derecho de la Universidad Pública de Navarra, uno sobre la familia pirenaica (2012) ${ }^{146}$ y el segundo sobre el régimen económico matrimonial (2014), que no ha sido objeto de publicación.

Los dos grandes sistemas familiares de Navarra, el troncal o de heredero único y el nuclear, han generado una amplísima producción desde los años ochenta. El matrimonio contemplado como un elemento más de análisis hacia la comprensión de la herencia familiar era un tema trabajado únicamente por juristas foralistas, hasta la irrupción de los trabajos desarrollados desde la demografía histórica. Alfredo Floristán Imízcoz estudió el caso de Tierra Estella, con especial atención sobre la villa de Cirauqui (1982) ${ }^{147}$, Ángel García-Sanz se centró en la Barranca (1985) ${ }^{148}$, Alejandro Arizcun Cela lo hizo sobre el valle de Baztan (1988) ${ }^{149}$, y, desde finales de los ochenta Fernando Mikelarena Peña ${ }^{150}$ y Pilar Erdozáin Azpilcueta $(1997,1999)^{151}$ han venido alumbrando una copiosa producción de extraordinario valor metodológico, conceptual y de erudición archivística. Ambos reflexionaron sobre las

${ }^{144}$ Con actas publicadas en la revista Vasconia. Cuadernos de Historia-Geografia, Vol. 28, 1999.

145 Fernández, C. y Moreno, A. (eds.), Familia y cambio social en Navarra y el País Vasco. Siglos XIII al XX. Simposio de Historia de la Familia. Pamplona, 20 y 21 de septiembre de 2002, Instituto de Ciencias para la Familia, Pamplona, 2003.

${ }^{146}$ Con actas publicadas en la revista Iura Vasconiae, 10, 2013, pp. 515-670.

147 Floristán Imízcoz, A., La Merindad de Estella en la Edad Moderna. Los hombres y la tierra, Institución Príncipe de Viana, Pamplona, 1982.

${ }_{148}$ García-Sanz Marcotegui, Á., Demografía y Sociedad de la Barranca de Navarra, 1760-1860, Gobierno de Navarra, Pamplona, 1985.

149 Arizcun Cela, A., Economía y Sociedad en un valle pirenaico del Antiguo Régimen. Baztán 1600-1844, Gobierno de Navarra, Pamplona, 1988.

${ }^{150}$ Mikelarena PeÑa, F., «Vecindad, igualitarismo, situación material», Gerónimo de Uztáriz, Vol. 3, 1989, pp. 5-17; «Estructuras familiares y sistemas sucesorios en Navarra: una aproximación crítica desde las ciencias sociales a las perspectivas tradicionales», Revista Jurídica de Navarra, Vol. 14, 1992, pp. 119-145; «Modelos de matrimonio y regímenes de herencia en Navarra a finales del siglo XVIII», Príncipe de Viana, Anejo 16, 1992, pp. 19-33; «Estructuras familiares en España y en Navarra en los siglos XVIII y XIX: factores etnoculturales, diferenciación socioeconómica y comportamientos estratégicos», Revista de Antropología Social, Vol. 2, 1993, pp. 105-136; Demografía y familia en la Navarra tradicional, Gobierno de Navarra, Pamplona, 1995.

${ }^{151}$ ERdozÁIn AzPILICUETA, P., «Familia y patrimonio en Navarra a finales del siglo XIX», en ChAcón Jiménez, F. y Ferrer i Alós, L. (eds.), Familia, casa y trabajo, Universidad de Murcia, Murcia, 1997, pp. 511-529; Propiedad, familia y trabajo en la Navarra contemporánea, Gobierno de Navarra, Pamplona, 1999. 
fuentes y posibilidades de investigación en torno a la familia troncal en $\mathrm{Na}$ varra, que incide, entre otros aspectos, en la importancia de los contratos matrimoniales y otros documentos notariales ${ }^{152}$, y desarrollaron análisis específicos sobre las estrategias matrimoniales en el sur (1999) ${ }^{153}$ y en el norte de Navarra (2004) ${ }^{154}$. Debemos anotar, además, el trabajo que Mikelarena desarrolló junto con Lola Valverde Lamsfus sobre los hijos ilegítimos $(1996)^{155}$, tema que ambos abordaron en sus respectivas tesis doctorales -en el segundo caso como objeto central de su estudio-, y que implica el análisis de las relaciones sexuales, permanentes o no, fuera del matrimonio ${ }^{156}$.

Diversos historiadores de la Universidad de Navarra han venido desarrollando importantes aportaciones en torno a las estrategias matrimoniales, individualizando la cuestión dentro de una potente línea de investigación dedicada a la Historia de la Familia, a lo que se consagró un Instituto específico

152 Erdozáin Azpilicueta, P. y Mikelarena Peña, F., «La familia troncal en Navarra: fuentes y aspectos a investigar», en Fernández, C. y Moreno, A. (eds.), Familia y cambio social en Navarra y el País Vasco. Siglos XIII al XX. Simposio de Historia de la Familia. Pamplona, 20 y 21 de septiembre de 2002, Instituto de Ciencias para la Familia, Pamplona, 2003, pp. 17-44. Vid., asimismo, otras reflexiones suyas anteriores en «Algunas consideraciones en torno a la investigación del régimen de herencia troncal en la Euskal Herria tradicional», Vasconia, Vol. 28, 1999, pp. 71-91.

153 Erdozáin Azpilicueta, P. y Mikelarena Peña, F., «Familia y nupcialidad en el valle medio del Ebro entre 1786 y 1930», en SALAS AuSENS, J. A. (coord.), La población del valle del Ebro en el pasado, Instituto de Estudios Riojanos, Logroño, 1999, pp. 43-70.

154 ERdozÁin AzPIlicueta, P. y Mikelarena PeÑa, F., «Las estrategias matrimoniales a través de los contratos matrimoniales en el Norte de Navarra», Iura Vasconiae, Vol. 2, 2004, pp. 485-522. Y con J. I. PAUL ARZAK son autores de los artículos «Las explotaciones agrarias y los hogares del campesinado arrendatario en la Navarra cantábrica», Príncipe de Viana, Vol. LXIII, n 225, 2002, pp. 231-261; «Las estrategias familiares de los campesinos propietarios de la Vasconia cantábrica. Una perspectiva microanalítica», Historia Social, Vol. 43, 2002, pp. 77-103; y «Hogares y caseríos en la Navarra cantábrica en el siglo XIX. Un enfoque microanalítico», Hispania, Vol. LXIII/1, nº 213, 2003, pp. 199-230.

«Las explotaciones agrarias y los hogares del campesinado arrendatario en la Navarra cantábrica», Príncipe de Viana, Vol. LXIII, n 225, 2002, pp. 231-261; «Las estrategias familiares de los campesinos propietarios de la Vasconia cantábrica. Una perspectiva microanalítica», Historia Social, Vol. 43, 2002, pp. 77-103.

155 Mikelarena Peña, F. y Valverde Lamsfus, L., «Ilegitimidad y exposición en Navarra (siglos XVI-XX)», en PÉREz MoredA, V. (coord.), Epostos e ilegítimos na realidade ibérica do século XVI ao presente. Actas do III Congresso da ADEH (Associaçao Ibérica de Demografia Histórica), Ediçoes Afrontamento, Porto, 1996, vol. 3, pp. 271-302.

156 Mikelarena Peña, F., Demografía y familia, op.cit., pp. 139-144; Valverde LAMSFUS, L., Entre el deshonor y la miseria. Infancia abandonada en Guipúzcoa y Navarra. Siglos XVIII y XIX, Universidad del País Vasco/Euskal Herriko Unibertsitatea, Bilbao, 1995. 
de ese centro académico. La tesis doctoral de Ana Zabalza Seguín se centró en el sistema de heredero único (1994) ${ }^{157}$, sobre lo que ha venido profundizando en estudios posteriores $(1999,2004)^{158}$, en ocasiones juntamente con Antonio Moreno Almárcegui (1999) ${ }^{159}$. Este autor, junto con Rocío García Bourrellier, lanzó una controvertida teoría para explicar el cambio en el modelo familiar de las elites nobiliarias navarras entre los siglos XV y XVII $(2003)^{160}$. Por su parte, César Ruiz Gómez concibió su tesis doctoral comparando, durante la época austracista, el sistema de heredero único con los regímenes hereditarios de igualdad entre hermanos $(2005)^{161}$. Otra tesis doctoral, la de Mikel Aranburu Zudaire, centrada en la presencia navarra en Indias entre los siglos XVI y XVII, no desatendió el marco matrimonial y sucesorio que movió a emigrar a aquellos hombres (1999) ${ }^{162}$.

Dentro de la historiografía sobre estrategias familiares hay que apuntar una línea de investigación centrada en el matrimonio de las elites. Se trata, en general, de investigaciones que apenas prestan atención a la propia institución matrimonial, pues buscan conocer mejor los intereses sociales, políticos

157 Zabalza Seguín, A., Aldeas y campesinos en la Navarra prepirenaica (15501817), Gobierno de Navarra, Pamplona, 1994.

158 Zabalza Seguín, A., «La historia de la familia en Navarra. Una aproximación cualitativa», Cuadernos de Investigación Histórica, Vol. 17, 1999, pp. 67-80; «El heredero ideal: prácticas sucesorias en la Navarra pierenaica durante la Edad Moderna (15501725)», en Sullivan, D. S. R. (coord.), Actas del Congreso Internacional de la Población. V Congreso de la ADEH, vol. IV. Matrimonio y nupcialidad: perspectivas interdisciplinares, Gobierno de La Rioja-Instituto de Estudios Riojanos, Logroño, 1999, pp. 239-250; «Casa e identidad social. La casa en la sociedad campesina: Navarra, 1550-1700», Imízcoz Beunza, J. Ma (ed.), Casa, familia y sociedad. País Vasco, España y América, siglos $X V$-XIX, Universidad del País Vasco/Euskal Herriko Unibertsitatea, Bilbao, 2004, pp. 79-95.

159 Nos limitaremos a citar su monografía Moreno Almárcegui, A. y Zabalza SEGUín, A., El origen histórico de un sistema de heredero único. El prepirineo navarro, 1540-1739, RIALP, Madrid, 1999.

160 Moreno Almárcegui, A. y García Bourrellier, R., «De los linajes a los solares. Los cambios en el papel de las mujeres en las elites navarras. Siglos XV al XVII», en FERnÁndez, C. y Moreno, A. (eds.), Familia y cambio social en Navarra y el País Vasco. Siglos XIII al XX. Simposio de Historia de la Familia. Pamplona, 20 y 21 de septiembre de 2002, Instituto de Ciencias para la Familia, Pamplona, 2003, pp. 217-250.

161 Ruiz Gómez, C., Las relaciones familiares en Navarra durante los Austrias (1530-1719). Un estudio comparado de dos comunidades con sistemas sucesorios distintos, Instituto de Ciencias para la Familia, Pamplona, 2005.

162 Aramburu Zudaire, J. M., Vida y fortuna del emigrante navarro a Indias (siglos XVI-XVII), Gobierno de Navarra, Pamplona, 1999. Previamente había adelantado algunas conclusiones en el trabajo que realizó junto con J. Ma UsunÁRIZ GARAYOA, «De la Navarra de los Austrias a la hora navarra del XVII en América», en ANDRÉS-GALLEGO, J. (coord.), Mapfre, Madrid, 1992, pp. 17-261. 
o económicos que movieron a las elites a la hora de diseñar los enlaces de sus vástagos. A pesar de ello, aportaciones como las de Fernando Cañada Palacio $(1987)^{163}$, María Raquel García Arancón $(1987)^{164}$, Eloísa Ramírez Vaquero $(1990)^{165}$, José Joaquín Noáin Irisarri $(2003,2004)^{166}$, José María Imízcoz Beunza $(2001)^{167}$ y Pablo Orduna Portús $(2009,2013)^{168}$ son de un elevado interés para el conocimiento de la práctica jurídica en la Navarra medieval y moderna.

Toda esta producción ha desembocado también en síntesis históricas, como la de Mercedes Vázquez de Prada $(1996)^{169}$, que observó la evolución de la institución desde el Antiguo Régimen hasta la actualidad, o la de Jesús María Usunáriz Garayoa y Rocío García Bourrellier (2012) ${ }^{170}$, donde además de analizar las estrategias matrimoniales, se fijaron en los aspectos más relevantes de la conflictividad conyugal. Este aspecto ha sido el objeto de estudio central de María del Juncal Campo Guinea, autora de la tesis doctoral titulada Comportamientos matrimoniales en Navarra. Siglos XVI y XVII

${ }^{163}$ Cañada Palacio, F., «Endogamia en la dinastía regia de Pamplona (siglos IX-XI)», Príncipe de Viana, Vol. XLVIII, n 182, 1987, pp. 781-787; «El círculo nobiliario y la familia regis en la monarquía pamplonesa hasta el siglo XI», Primer Congreso General de Historia de Navarra, 3, Comunicaciones. Príncipe de Viana, Anejo 8, Vol. XLVIII, 1987, pp. 19-25.

164 García Arancón, M ${ }^{\mathrm{a}}$ R., «Carlos II de Navarra: el círculo familiar», Príncipe de Viana, Vol. XLVIII, no 182, 1987, pp. 569-608.

165 Ramírez VAQuero, E., Solidaridades nobiliarias y conflictos políticos en Navarra, 1387-1464, Gobierno de Navarra, Pamplona, 1990.

166 NoÁIN IRISARRI, J. J., «Estrategias económico-familiares de la nobleza media de Navarra en la Edad Moderna (1500-1700)», en FERnÁndez, C. y Moreno, A. (eds.), Familia y cambio social en Navarra y el País Vasco. Siglos XIII al XX. Simposio de Historia de la Familia. Pamplona, 20 y 21 de septiembre de 2002, Instituto de Ciencias para la Familia, Pamplona, 2003, pp. 91-164; «Nobleza Media y transmisión del patrimonio familiar en la Navarra moderna», Iura Vasconiae, Vol. 1, 2004, pp. 523-550.

${ }^{167}$ Imízcoz Beunza, J. M $\mathrm{M}^{\mathrm{a}}$, «El patrocinio familiar. Parentela, educación y promoción de las elites vasco-navarras en la monarquía borbónica», en CHACÓN JIMÉNEZ, F. y HERNÁNDEZ Franco, J. (eds.), Familias, poderosos y oligarquías, Universidad de Murcia, Murcia, 2001, pp. 93-130.

168 Orduna Portús, P., Honor y cultura nobiliaria en la Navarra moderna (siglos XVI-XVIII), EUNSA, Barañáin, 2009; «Estructuras familiares de las élites navarras durante el Antiguo Régimen», EHumanista: Monograph Series, Vol. 5, 2009, pp. 1-82; «Amor y violencia entre la nobleza navarra (siglos XVI-XVIII)», EHumanista: Monograph Series, Vol. 25, 2013, pp. 195-210.

169 VÁzquez de Prada Tiffé, M., «Casamiento y familia», en Beguiristáin, Ma A. (dir.), Etnología de Navarra, Diario de Navarra, Pamplona, 1996, vol. 2, pp. 337-350.

170 García Bourrellier, R. y UsunÁriz Garayoa, J. Ma , Amar y convivir. Matrimonio y familia en Navarra (siglos XIII-XVI), Gobierno de Navarra-Caja de Ahorros de Navarra/Banca Cívica-Diario de Navarra, Pamplona, 2012. 
$(1998)^{171}$, que concibió desde una perspectiva eminentemente social. Adelantó algunos datos y conclusiones en tres trabajos previos publicados a mediados de los noventa ${ }^{172}$, y, con posterioridad, ahondó y volvió a reflexionar sobre diversas cuestiones planteadas en su monografía $(2004,2005)^{173}$. Campo Guinea desarrolló una investigación sistemática de los fondos del Archivo Diocesano de Pamplona de los siglos XVI y XVII a través de una meritoria metodología de historia cuantitativa.

Los procesos de los Tribunales Reales custodiados en el Archivo General de Navarra han sido extractados por el investigador Fernando Maiora Mendía (2012) ${ }^{174}$, limitándose a transcribir los fragmentos de los textos procesales que le llamaban la atención por su escabrosidad, sin realizar análisis alguno.

No disponemos de procesos judiciales medievales, de ahí que la reconstrucción de la conflictividad en el seno de la pareja haya de realizarse a través de otras fuentes, como los registros de comptos, tarea acometida por la tesis doctoral de Félix Segura Urra dedicada a la Justicia bajomedieval navarra, en la que dedicó una atención especial al estudio de los delitos sexuales, entre los que nos interesa resaltar el adulterio y la violación y rapto $(2005)^{175}$, aspectos, algunos de ellos, en los que profundizó en otros dos estudios $(2002,2005,2007)^{176}$. La tesis doctoral de Marcelino Beroiz, desarro-

171 CAmpo Guinea, M ${ }^{\mathrm{a}}$ del J., Comportamientos, op.cit.

172 CAmpo Guinea, $M^{\mathrm{a}}$ del J., «Los procesos por causa matrimonial ante el tribunal eclesiástico de Pamplona en los siglos XVI y XVII», Príncipe de Viana, Vol. LV, $\mathrm{n}^{\circ} 202$, 1994, pp. 377-390; «La ruptura matrimonial en Navarra a través de la actividad procesal del tribunal eclesiástico de Pamplona», Huarte de San Juan. Geografía e Historia, Vol. 1, 1994, pp. 115-134; «La fuerza, el otro lado de la voluntad. El matrimonio en Navarra en los siglos XVI-XVII», Boletín del Instituto Gerónimo de Ustáriz, Vol. 11, 1995, pp. 71-87.

${ }^{173}$ CAmpo GuineA, $M^{a}$ del J., «El matrimonio clandestino: procesos ante el Tribunal Eclesiástico en el Archivo Diocesano de Pamplona (siglos XVI-XVII)», Príncipe de Via$n a$, Vol. LXV, $\mathrm{n}^{\circ}$ 231, 2004, pp. 205-222; «Evolución del matrimonio en Navarra en los siglos XVI y XVII: el matrimonio clandestino», en ARELLANO, I. y USUNÁRIZ, J. Ma (eds.), El matrimonio en Europa y en el mundo hispánico: siglos XVI y XVII, Visor, Madrid, 2005, pp. 197-210.

${ }_{174}$ Maiora Mendía, F., La jodienda, sin enmienda. Putas, clérigos, mal casadas, doncellas, maricones, bujarrones, zoofilia, Edic. del autor, Pamplona, 2012.

175 Segura Urra, F., Fazer justicia. Fuero, poder público y delito en Navarra (siglos XIII-XIV), Gobierno de Navarra, Pamplona, 2005.

176 Segura UrRa, F, «Víctimas y agresoras: la mujer ante la justicia en Navarra durante la primera mitad del siglo XIV», en V Congreso General de Historia de Navarra, I, Sociedad de Estudios Históricos de Navarra, Pamplona, 2002, pp. 145-167; «Verba vituperosa: el papel de la injuria en la sociedad bajomedieval», GARCíA BOURRELLIER, R. y UsunÁriz, J. Ma (eds.), Aportaciones a la historia social del lenguaje. España, siglos 
llada sobre el mismo tema y publicada el mismo año (2005), también trabajó ambos delitos ${ }^{177}$.

La abundancia de los estudios de Historia social permitirá conocer, en investigaciones futuras, si el reino de Navarra era especialmente problemático en relación con el matrimonio, al menos desde una perspectiva comparada con otros reinos. Cabe abordar también estudios comparativos entre diversos reinos a partir del número de procesos matrimoniales vistos en las diversas jurisdicciones.

Para la Edad Contemporánea, además de los trabajos ya mencionados de Mikelarena, Erdozáin y Valverde, contamos con la tesis doctoral de Fernando Mendiola (2002) ${ }^{178}$, centrada en la transformación del modelo familiar en el mundo urbano contemporáneo. Cabe mencionar, asimismo, el artículo de Claudio Zudaire Huarte sobre la consanguinidad en los valles del BidasoaBaztan en el siglo XX (1982) ${ }^{179}$.

Resta decir que la inmensa mayoría de los historiadores generalistas todavía no han sido capaces de recurrir en sus estudios a la doctrina elaborada por los juristas. El desdén alcanza tal extremo que aquellos llegan a invocar doctrina sobre fuentes jurídicas castellanas para ilustrar una realidad histórica navarra y dotarla de un cierto marco teórico, ignorando, a su vez, los estudios sobre las fuentes jurídicas navarras existentes sobre el particular. Sirva de ejemplo el tratamiento otorgado al Fuero General de Navarra por Jesús María Usunáriz y Rocío García Bourrellier en su monografía sobre el matrimonio y la familia navarra entre los siglos XIII y XVI: tras describir detenidamente la regulación del matrimonio castellano en Partidas -a partir de la obra del trabajo clásico de Antonio Mostaza Rodríguez-, reducen la rica, compleja y singular legislación navarra a señalar que el «Fuero General dedicaba uno de sus capítulos [sic] a los casamientos, aunque sin tanta precisión como la legislación castellana» ${ }^{180}$. Tal aseveración encierra un desconocimiento profundo de la fuente, pues la regulación de los casamientos está recogida en numerosos capítulos, a lo que se añade la ignorancia de que la diferencia entre el matrimonio del Fuero General y de Partidas estriba,

$X I V$-XVIII, Iberoamericana-Vervuert, Madrid-Frankfurt, 2005, pp. 149-195; «La pena de muerte en la Navarra medieval», Clio \& Crimen, Vol. 4, 2007, pp. 277-305.

177 Beroiz LazCano, M., Crimen y castigo en Navarra bajo el reinado de los primeros Evreux (1328-1349), Universidad Pública de Navarra/Nafarroako Unibertsitate Publikoa, Pamplona, 2005, pp. 203-222.

178 Mendiola Gonzalo, F., Inmigración, familia y empleo. Estrategias familiares en los inicios de la industrialización, Pamplona (1840-1930), Universidad del País Vasco/ Euskal Herriko Unibertsitatea, Bilbao, 2002.

179 Zudaire Huarte, C., "Consanguinidad en Baztán, Santesteban y Cinco Villas», Cuadernos de Etnología y Etnografia de Navarra, Vol. 40, 1982, pp. 723-751.

${ }^{180}$ UsunÁriz, J. Ma . y GARCÍA Bourrellier, R., Amar y convivir, op.cit., p. 16. 
nada menos, en la no recepción del Ius commune en el texto navarro, lo que imprime un arcaísmo tan acusado a la institución, que se rige por unos parámetros muy alejados respecto de lo contenido en la magna obra alfonsina. Cabe verter consideraciones similares sobre el escaso tratamiento que los historiadores, por lo general, han mostrado por el marco canónico conciliar y sinodal.

El desinterés de los historiadores sociales por los estudios jurídicos lleva implícito el hecho de que no hayan sido capaces de ahondar suficientemente en la relevancia de los efectos legales de la conflictividad conyugal sobre el patrimonio y sobre las relaciones personales (la tutela y la custodia de los hijos).

Otro defecto observado arrastrado por estos autores y frecuentemente criticado desde la Historia del Derecho para otros ámbitos geográficos, es la utilización de conceptos jurídicos insuficientemente comprendidos y, por tanto, mal empleados. El desconocimiento ya advertido de la labor desarrollada desde la Historia del Derecho o desde el Derecho positivo, implica la no asimilación del bagaje conceptual preciso de la institución. Cierto es que la utilización de fuentes jurídicas no tiene como fin, en algunos trabajos, el establecimiento de categorías o efectuar análisis jurídicos; muy al contrario, pretenden contribuir al conocimiento de la institución matrimonial en la Historia de Navarra, las relaciones sociales implicadas, la mentalidad de cada época, la economía de la pareja y de la familia, o el medio cultural en que se desarrolla.

\subsection{La historiografia de género}

Los estudios dedicados a la mujer desde la historiografía social y de las mentalidades acabaron por alcanzar una autonomía a partir de los años setenta, toda una línea de investigación de lo que los anglosajones vinieron a denominar gender studies (estudios de género), y que desde entonces ha venido cambiando la imagen de las mujeres como sujeto pasivo en la Historia. La primera aportación iushistoriográfica que centrada en la mujer vasco-navarra la realizó Luis Miguel Díez de Salazar, analizando, su tratamiento en la legislación de los siglos XII-XIV.

Los estudios de género no se pueden disociar, por otro lado, de la historiografía feminista, que venía investigando el matrimonio como mecanismo de control social sobre la mujer ${ }^{181}$. Desde esta perspectiva, Miren Epalza

${ }^{181}$ Cfr. Pelizzari, M. R. (a cura di), Le donne e la storia. Problemi di metodo e confronti storiografici, Edizioni Scientifiche Italiane, Napoli, 1995. RIVERA GARRETAS, M ${ }^{a}$ M., "Corrientes historiográficas en el análisis de la presencia de las mujeres en la historia», en La mujer en la historia de Euskal Herria, Colecc. Langaiak, nº 12, IPES, Bilbao, 1988, pp. 7-12. 
Ronkal está desarrollando actualmente su tesis doctoral en Derecho en la Universidad Pública de Navarra sobre la violación en la Navarra medieval y moderna.

La historiografía social feminista cuenta con la obra divulgativa Ellas. Las mujeres en la historia de Pamplona (1998), donde se incluyó una síntesis relativa al matrimonio ${ }^{182}$. Pero esta línea de investigación tiene en Navarra un nombre propio: Lola Valverde Lamsfus, autora de diferentes artículos construidos desde una sólida base metodológica y un rastreo documental de los fondos del Archivo Diocesano de Pamplona $(1988,1991,1995)^{183}$. Por su parte, la medievalista María del Carmen García Herrero se ocupó del matrimonio en el fuero de Jaca en su monografía miscelánea sobre las mujeres en la Edad Media (2009) ${ }^{184}$.

Alejados de planteamientos feministas pero desde una inequívoca voluntad de realizar una investigación de género, Amaia Nausia Pimoulier, desarrolló su tesis doctoral la viudedad navarra, sobre lo que ha venido publicando diferentes estudios publicados entre el año 2008 y el $2013^{185}$. Asimismo, el historiador David Maruri ofreció algunos datos sobre la institución matrimonial en su estudio sobre la mujer en Sangüesa (2005) ${ }^{186}$.

182 Fernández, S., RodA, P. (coords.), Díez de Ure, A., Pinillos, S., Ellas. Las mujeres en la historia de Pamplona, Ayuntamiento de Pamplona, Pamplona, 1998, pp. 100-110.

183 VALVERDE LAMSFUS, L., "Contexto social y situación de la mujer vasca en el Antiguo Régimen», en La mujer en la historia de Euskal Herria, Colecc. Langaiak, $\mathrm{n}^{\circ}{ }^{12}$, IPES, Bilbao, 1988, pp. 35-45; «La influencia del sistema de transmisión de la herencia sobre la condición de las mujeres en el País Vasco en la Edad Moderna», Bilduma, Vol. 5, 1991, pp. 123-135; «Mujer y transmisión del patrimonio, Valle de Larraun, siglos XVII-XIX», Sukil, Vol. 1, 1995, pp. 52-56; VAlVERDE LAMSFus, L., Entre el deshonor y la miseria.

${ }^{184}$ García Herrero, Ma C., Artesanas de vida. Mujeres de la Edad Media, Institución Fernando el Católico, Zaragoza, 2009.

185 NAusia Pimoulier, A., «Suegros, nueras y viudas ante los Tribunales: la restitución de dotes (siglos XVI-XVII)», en UsunÁrIZ, J. Ma y GARCía Bourrellier, R. (eds.), Padres e hijos en España y el mundo hispánico. Siglos XVI y XVII, Visor Libros, Madrid, 2008, pp. 245-266; «Mujeres sometidas, mujeres descarriadas. El disciplinamiento de la mujer navarra en el siglo XVI», en 1512. Euskal lurraldeak eta nafar Estatua. Los territorios vascos y el Estado Navarro. Actas del II Congreso de Historiadores de Navarra, Txertoa, Donostia, 2011, pp. 307-352; «El usufructo de viudedad navarro como recurso de supervivencia para las viudas (siglos XVI y XVII)», Iura Vasconiae, Vol. 10, 2013, pp. 573-596; ¿Virgenes o putas?: 500 años de adoctrinamiento femenino (1512-2012), Erein, Donostia-San Sebastián, 2012; «El usufructo de viudedad navarro como recurso de supervivencia para las viudas (siglos XVI y XVII)», Iura Vasconiae, Vol. 10, 2013, pp. 573-596. Además de estas obras, publicó junto con J. BALdó Alcoz, Ser mujer (siglos XIII-XVI), Gobierno de Navara-Caja de Ahorros de Navarra/Banca Cívica-Diario de Navarra, Pamplona, 2012.

186 Maruri OrRantia, D., «La mujer en Sangüesa-Zangotza: algunas noticias para un estudio más profundo», Zangotzarra, Vol. 9, 2005, pp. 11-74. 


\subsection{Antropología social, Sociología y Sociología del Derecho}

El matrimonio ha constituido uno de los campos clásicos para el análisis de la Antropología social y de la Sociología, no en vano, la que se vino a denominar Antropología del parentesco supuso el germen durante la segunda mitad del siglo XIX de la Antropología contemporánea. Entre los precursores de esta línea de investigación se cuenta el sociólogo y economista francés Frédéric Le Play, que analizó la evolución histórica de la familia a partir del destacado trabajo de campo que le había llevado a recorrer toda Europa. Dedicó una atención especial a la familia pirenaica, la famille souche, que consideró singular por su estructura basada en la troncalidad y el heredero único ${ }^{187}$. Sus tesis fueron incorporadas a partir de entonces por todos los investigadores pirenaicos -incluidos los vasco-navarros-, hasta que fueron objeto de revisión en los años setenta del siglo XX por iushistoriadores como Jacques Poumarède ${ }^{188}$.

La realidad descrita por Le Play en los años ochenta del siglo XIX sufría ya una destacada regresión geográfica en 1916, cuando Hilario Yaben desarrolló su monografía ya citada ${ }^{189}$. Medio siglo después, el sistema se resquebrajaba incluso en los valles pirenaicos, lo que motivó la reactivación de las investigaciones antropológicas sobre la sucesión troncal y el sistema de heredero único, y su relación con la casa. Lo advirtieron Julio Caro Baroja (1982) ${ }^{190}$, Ramón Violant i Simorra (1985) ${ }^{191}$, William A. Dou-

187 LE Play, F., L'organisation de la famille : selon le vrai modèle signalé par l'histoire de toutes les races et de tous les temps. $2^{\mathrm{a}}$ edic. rev. y corr. A. Mame, Tours; Dentu, Paris, 1875 ( $1^{\mathrm{a}}$ ed. de 1871). Vid., sobre el particular, AsSIER-ANDREU, L., «Le Play et la famille souche des Pyrénées : politique, juridisme et science sociale», Anales ESC, Vol. 3, 1984, pp. 495-514.

188 Poumarède, J., «La famille pyrénéenne : état de la question», en Minovez, J.-M. y Souriac, R. (dirs.), Les hommes et leur patrimoine en Comminges, Saint-Gaudens, Féd. hist. de Midi-Pyrénées-Société des Études de Commiges, 2001, pp. 25-33. Reed. Itinéraire(s) d'un historien du droit. Jacques Poumarède, regards croisés sur la naissance de nos institutions, articles réunis et édités par J. P. Allinne, Toulouse, CNRS-Université de Toulouse II-Le Mirail, 2011, pp. 29-36; traducido por RiCO ARRASTIA, Mª I., «La familia pirenaica: un estado de la cuestión», Iura Vasconiae, Vol. 10, 2013, pp. 543-556; «Famille et tenure dans les Pyrénées du Moyen Âge au XIX ${ }^{\mathrm{e}}$ siècle», Annales de démographie historique, 1979, pp. 347-360. Reed. Itinéraire(s), op. cit., pp. 17-27; traducido por Rico Arrastia, M I., «Familia y propiedad en los Pirineos de la Edad Media al siglo XIX», Iura Vasconiae, Vol. 10, 2013, pp. 557-572.

189 YABEN Y YABEN, H., Los contratos, op.cit.

190 Caro Baroja, J., De la vida rural vasca, Txertoa, San Sebastián, 1982; La casa en Navarra, Caja de Ahorros de Navarra, Pamplona, 1982. 4 vols.

191 Violant i Simorra, R., El Pirineo español. Vida, usos, costumbres, creencias y tradiciones de una cultura milenaria que desaparece, Alta Fulla, Barcelona, 1985, pp. 265-303, sobre nacimiento, matrimonio y muerte. 
glass (1988) ${ }^{192}$, Jeremy MacClancy $(1991)^{193}$, Gabriel Imbuluzqueta $(2005)^{194} \mathrm{y}$ el tomo dedicado a la casa y la familia del Atlas etnográfico de Vasconia elaborado por el grupo Etniker Euskalerria $(2011)^{195}$. La crisis de la casa navarra está indisociablemente unida la crisis del matrimonio actual y a la consiguiente obsolescencia del régimen económico-matrimonial y sucesorio navarro, aspecto que ha tratado sucintamente Lidia Montesinos Llinares (2013) ${ }^{196}$.

En cuanto a las investigaciones de Antropología histórica centradas en la praxis matrimonial, José María Satrustegi trató prolijamente sobre el matrimonio en su libro Comportamiento sexual de los vascos $(1981)^{197}$, donde acarreó toda la prolija labor de exhumación y publicación previa de los procesos judiciales pretridentinos sobre promesas matrimoniales en euskera, de los que hemos dado cuenta al tratar sobre la historiografía canónica. A partir de los estudios de Satrustegi apenas han aparecido nuevas aportaciones, hecha salvedad de estudios etnográficos locales, cuyas referencias bibliográficas pueden rastrearse en el tomo del Atlas etnográfico de Vasconia dedicado a los ritos desde el nacimiento al matrimonio, desarrollado por Etniker Euskalerria (1998), obra imprescindible para conocer diferentes costumbres locales en relación a la institución matrimonial de los siglos XIX y XX ${ }^{198}$.

Los juristas, sin embargo, no han mostrado demasiado interés por la Antropología o la Sociología jurídica del matrimonio, hecha salvedad de Gabriel García Cantero, autor de un estudio sobre la filiación extramatrimonial del primer lustro de los años setenta (1976-1977) ${ }^{199}$, y de Juan Cruz Alli Aranguren, que reflexionó sobre la familia navarra de la primera década del siglo XXI $(2010)^{200}$.

192 Douglass, W. A., «The Basque Stem Family Household. Myth or Reality», Journal of Family History, Vol. 13/1, 1988, pp. 75-89.

193 MacClancy, J., «Navarra», en Antropología de los Pueblos del Norte de España, Universidad Complutense-Universidad de Cantabria, Madrid, 1991, pp. 118-120.

${ }^{194}$ ImbuluzQueta Alcasena, G., Navarra. Etnografia, Gobierno de Navarra, Pamplona, 2005, pp. 77-82.

195 Etniker Euskalerria, Casa y familia en Vasconia, Colecc. Atlas etnográfico de Vasconia, $n^{\text {o }}$ 1-2, Instituto Labayru, Bilbao, 2011.

196 Montesinos Llinares, L., Iraliku'k: la confrontación de los comunales. Etnografia e historia de las relaciones de propiedad en Goizueta, dirigida por el Dr. Ignasi Terradas, Facultad de Filosofía y Letras, Universidad de Barcelona, 2013.

197 Satrústegui, J. Ma ${ }^{\mathrm{a}}$, Comportamiento sexual de los vascos, Txertoa, San Sebastián, 1981.

198 Etniker Euskalerria, Ritos del nacimiento al matrimonio, Colecc. Atlas etnográfico de Vasconia, no 9, Instituto Labayru, Bilbao, 1998.

199 García Cantero, G., «Sociología de la filiación extramatrimonial en Pamplona (años 1973 y 1974)», Anuario de Derecho Foral, Vol. 2, 1976-1977, pp. 325-336.

200 Alli Aranguren, J. C., «Notas sobre la consideración socio-jurídica de la familia navarra al inicio del siglo XXI», Príncipe de Viana, Vol. LXXI, nº 250, 2010, pp. 553-605. 
TITLE: Examination of the Sources for the Study of the History of Marriage and Unmarried Couples: An Approach from Navarre.

RESUMEN: El presente trabajo analiza las fuentes para el estudio de la Historia del matrimonio y de las uniones permanentes a través del ejemplo de Navarra que, en relación al régimen económico-matrimonial, suponen la base historicista sobre la que se redactó el Fuero Nuevo de 1973. Recorremos, en concreto, la costumbre, las fuentes legislativas civiles y las canónicas, la documentación procesal, la documentación notarial, los registros de Comptos del reino, los registros parroquiales y civiles, las visitas episcopales, las fuentes estadísticas y las fuentes doctrinales, diferenciando, en estas últimas, las diferentes perspectivas metodológicas que se han acercado a la historia jurídica del matrimonio $y$ de las uniones estables.

PALABRAS CLAVE: Fuentes del Derecho, Historia del Derecho, Matrimonio, Parejas de hecho, Navarra.

ABSTRACT: This paper analyzes the sources for the study of the History of Marriage and Unmarried couples through the example of Navarre; these represent the historicist basis on which the Foral Civil Compilation of 1973 was written. We takes into account in particular, customary law, civil and canonical legislative sources, procedural documentation, notarized documentation, Account records of de Kingdom, Parish and Civil records, episcopal visits, statistical sources and doctrinal sources, identifying, in the latter, the different methodological perspectives that have approached the Legal History of Marriage and Unmarried couples.

KEY WORDS: Sources of law, History of Law, Marriage, Unmarried couples, Navarre. 